\title{
A LEGITIMAÇÃO DE DECISÕES JURÍDICAS NA UTILIZAÇÃO DE LEGAL TECHNOLOGY
}

\section{Wolfgang Hoffman-Riem}

Professor Catedrático Emérito da Universidade de Hamburgo. Professor da Bucerius School of Law, Hamburgo. Ex-Juiz do Tribunal Constitucional Federal da Alemanha.

\begin{abstract}
Resumo: Legal Technology (Legal Tech) é um termo que se refere ao uso de técnicas digitais para aplicar e fazer cumprir a lei. Para os advogados, atualmente está surgindo um mercado para novos serviços jurídicos. Além disso, as administrações públicas e os tribunais também estão usando as possibilidades oferecidas pela digitalização. 0 presente artigo discute 0 aprimoramento de algoritmos em algoritmos de aprendizado, bem como o uso de big data. Ele analisa as diferenças entre decisões humanas como construções sociais e decisões algorítmicas como construções técnicas. Também descreve as oportunidades e dificuldades associadas à modelagem da lei ao software digital. As regras atuais contidas no Regulamento Geral de Proteção de Dados da UE e na lei alemã da administração pública, mas também a sanção automatizada de violações da lei na área de contratos inteligentes, servem como exemplos de abordagens que estão sendo praticadas.
\end{abstract}

Palavras-chave: Tecnologia jurídica. Aplicação da lei. Algoritmos. Big data. Tomada de decisão.

Sumário: 1 Legal Technology como fenômeno da digitalização da forma de lidar com o direito 2 Sistemas inteligentes baseados em algoritmos - 3 Um caso especial: a utilização de big data 4 Funções do direito - $\mathbf{5}$ Garantia de vinculação às regras em forma de construtos sociais e tecnológicos - $\mathbf{6}$ Requisitos de legitimação - $\mathbf{7}$ Requisitos para decisões automatizadas - $\mathbf{8}$ Requisitos para uma execução de decisões automatizadas - $\mathbf{9}$ Governança por algoritmos - Referências

\section{Legal Technology como fenômeno da digitalização da forma de lidar com o direito}

\subsection{Transformação digital}

A digitalização da comunicação e de atividades dependentes da comunicação acarreta problemas subsequentes em quase todos os setores da sociedade. Isso justifica que se fale da transformação digital da economia, cultura, política, comunicação pública e privada e muitas outras áreas. ${ }^{1}$ Com isso também mudam os focos de atenção.

1 Quanto à transformação digital, veja, pars pro toto, COLE, Tim. Digitale Transformation. Munich: Vahlen, 2015; KEESE, Christoph. Silicon Germany. Wie wir die digitale Transformation schaffen. Munich: Albrecht Knaus Verlag, 2016; STENGEL; VAN LOOY; WALLASCHKOWSKI (Ed.). Digitalzeitalter - Digitalgesellschaft: 
Ao passo que desde o final do século passado as discussões públicas estavam, em muitos casos, concentradas primordialmente nas oportunidades e riscos da internet e, especialmente, na proteção da personalidade e dos dados, outros fenômenos também se encontram, em grau crescente, no foco da atenção pública e científica. Deles fazem parte, entre outros, a globalização das infraestruturas comunicacionais e dos mercados que as marcam, big data, inteligência artificial e robótica, bem como os efeitos daí resultantes sobre desdobramentos fundamentais que ocorrem na sociedade. Além de consequências para os interesses de indivíduos - p. ex., ampliação da autonomia e ameaças a ela -, interesses coletivos estão sendo enfocados de modo cada vez mais acentuado, o que é desencadeado pelas mudanças na produção e na vida profissional, no atendimento à saúde, na mobilidade, na influência exercida sobre eleições políticas e muitas outras áreas. ${ }^{2}$

Tais mudanças também não deixam de se refletir no ordenamento jurídico, cujas estruturas básicas e expressões concretas provêm do "universo analógico". É de se perguntar até que ponto elas ainda estão à altura da transformação digital ou precisam se reajustar a ela. Outras perguntas que surgem são se os portadores de responsabilidade política podem efetivar a adaptação de modo orientado pelo bem comum e também se a ciência, incluindo a ciência jurídica, está preparada para participar desse processo oferecendo apoio. Neste contexto também estão em pauta o desenvolvimento e a implementação de abordagens inovadoras para o enfrentamento de novos problemas nos diversos setores da sociedade e nos ordenamentos jurídicos parciais com eles relacionados. A isso se associa a questão das possibilidades de utilização de tecnologias digitais na criação do direito, na consultoria jurídica e na aplicação do direito.

Das Ende des Industriezeitalters und der Beginn einer neuen Epoche. New York: Springer VS, 2017; PFLIEGL; SEIBT. Die digitale Transformation findet statt! e\&i Elektrotechnik und Informationstechnik, v. 7, p. 333-339, 2017; ROLF, Arno. Weltmacht Vereinigte Daten: Die Digitalisierung und big data verstehen. Berlim: Metropolis Verlag, 2018; KOLANY-RAISER; HEIL; ORVAT; HOEREN (Ed.). Big data und Gesellschaft. Eine multidisziplinäre Annäherung. New York: Springer VS, 2018. Preponderantemente do ponto de vista filosófico: PRECHT, Jäger. Hirten, Kritiker. Eine Utopie für die digitale Gesellschaft. Munich: Goldmann Verlag. 2018.

2 Quanto aos temas abordados, veja, pars pro toto, as contribuições em SÆTMAN; SCHNEIDER; GREEN (Ed.). The Politics of big data: big data, Big Brother? Abingdon: Routledge, 2018 apud KOLANY-RAISER; HEIL; ORVAT; HOEREN (Ed.). Big data und Gesellschaft. Eine multidisziplinäre Annäherung. New York: Springer VS, 2018, bem como em RADEMACHER; WISCHMEYER (Ed.). Regulating Artificial Intelligence. New York: Springer, 2019. 


\subsection{Legal Technology}

O campo temático mencionado por último se situa no marco mais amplo da utilização de Legal Technology - Legal Tech, na forma abreviada. ${ }^{3}$ A Legal Tech é empregada principalmente - mas não só - no âmbito jurídico anglo-saxão. Também na Alemanha tecnologias digitais estão sendo empregadas em diversas áreas do ordenamento jurídico, e o discurso científico sobre isso já teve início. ${ }^{4}$ Impulsionado principalmente pelos advogados e advogadas, está se formando atualmente um "mercado de Legal Tech" à parte, especialmente como mercado (do setor privado) para a prestação de serviços jurídicos, ${ }^{5}$ p. ex. para a consultoria jurídica automatizada, portais de especialistas em direito ou implementação do direito baseada em algoritmos. Mas também os tribunais e órgãos estatais estão se voltando para a digitalização e utilizando suas possibilidades. Algumas leis já estão regulamentando agora formas de comunicação jurídica digital, chegando até a admissão de decisões automatizadas (quanto a isso, veja seções 7 e 8 abaixo). Também há formas de resolução digital de litígios, como na modalidade da Online Dispute Resolution (Resolução de Litígios On-line). ${ }^{6}$

Novas tecnologias também estão sendo usadas para finalidades relacionadas ao direito. Por exemplo, a tecnologia Blockchain ${ }^{7}$ para registro de transações - uma tecnologia de base $-{ }^{8}$ possibilita aplicações específicas, como o armazenamento de dados juridicamente relevantes em busca de credibilidade, a criação e o tratamento dos chamados Smart Contracts, ${ }^{9}$ a remuneração confiável de produtos

3 Quanto a esse assunto já existem manuais ou livros-texto também em alemão: HARTUNG; BUES; HALBLEIB (Ed.). Legal Tech: Die Digitalisierung des Rechtsmarkts. Munich: C.H.Beck, 2018; BREIDENBACH; GLATZ (Ed.). Rechtshandbuch Legal Tech. Munich: C.H.Beck, 2018.

4 Mencionem-se como exemplos RAABE; WACKER. Recht ex machina: Formalisierung des Rechts im Internet der Dienste. New York: Springer, 2012; KOTSOGLOU. Subsumtionsautomat 2.0. JZ, 2014. p. 451 ss.; FRESE. Recht im zweiten Maschinenzeitalter. NJW, 2015. p. 2090 ss.; BUCHHOLTZ, Gabriele. Legal Tech: Chancen und Risiken der digitalen Rechtsanwendung. JuS, 2017. p. 955 ss.; BOEHME-NEßLER, Volker. Die Macht der Algorithmen und die Ohnmacht des Rechts: Wie die Digitalisierung das Recht relativiert. NJW, 2017. p. 3031 ss.; WAGNER. Legal Tech und Legal Robots in Unternehmen und den diese beratenden Kanzleien. BB, 2017. p. 88 ss.; ERNST. Algorithmische Entscheidungsfindung und personenbezogene Daten. JZ, 2017. p. 1026 ss.; KLAFKI; WÜRKERT; WINTER (Ed.). Digitalisierung und Recht. Hamburg: Bucerius Law School Press, 2017.

5 Veja, pars pro toto, TOBSCHALL; KEMPE. Der deutsche Legal-Tech-Markt. In: BREIDENBACH; GLATZ (Ed.). Rechtshandbuch Legal Tech. Munich: C.H.Beck, 2018. p. 25 ss.

6 Quanto a isso, veja BRAEGELMANN. Online-Streitbeilegung (Online Dispute Resolution - ODR). In: HARTUNG; BUES; HALBLEIB (Ed.). Legal Tech: Die Digitalisierung des Rechtsmarkts. Munich: C.H.Beck, 2018. p. 215 ss.

7 Quanto a isso, veja, pars pro toto, RIEGERER. Transparenz von Lieferketten durch die Blockchain. In: BREIDENBACH; GLATZ (Ed.). Rechtshandbuch Legal Tech. Munich: C.H.Beck, 2018. p. 100 ss.

8 Segundo GLATZ. Blockchain - ein Paradigmenwechsel? In: BREIDENBACH; GLATZ (Ed.). Rechtshandbuch Legal Tech. Munich: C.H.Beck, 2018. p. 59; 73 ss.

9 Quanto a eles, veja HECKELMANN. Zulässigkeit und Handhabung von Smart Contracts. NJW, 2018. p. 504 SS.; ESCHENBRUCH. Smart Contracts. NZBau, 2018. p. 3 ss.; MÜLLER. Bitcoin, Blockchain und Smart 
ou serviços protegidos pela legislação do direito autoral, a melhoria de etapas do processamento de dados no E-Government (Governo Eletrônico), ${ }^{10}$ p. ex., ou a criação de registros digitais, como ex., cadastros de imóveis.

Na utilização de tecnologias digitais, um elemento que até agora caracterizava a criação e aplicação do direito é abandonado, ao menos em parte: a ação humana. Em vez disso, o processamento é confiado ao computador e ao software utilizável com a ajuda dele ou ao chamado agente de software. ${ }^{11}$ Isso pode se limitar à preparação da decisão, mas também levar a um processo automatizado de tomada de decisões com um resultado produzido de forma automatizada ou também a uma criação de direito automatizada. Embora tais decisões não representassem o fim do direito, elas transformariam sua forma de funcionamento e poderiam influenciar o tipo e os resultados do cumprimento de funções jurídicas. ${ }^{12}$

Como vantagens da Legal Tech se mencionam, p. ex., possibilidades de uma melhor pesquisa e avaliação de fontes jurídicas, e também de precedentes administrativos e judiciais para, p. ex., fins de consultoria jurídica ou condução estratégica do processo judicial. O que se espera disso é uma economia considerável de custos, mas também o aumento da rapidez, eficiência e efetividade não só da consultoria jurídica, mas também da preparação e tomada de decisões e de sua execução. A Legal Tech também possibilita a eliminação de barreiras para o acesso ao direito. ${ }^{13}$

Entre os possíveis riscos se encontra a erosão da validade prática de fatores de controle não automatizados ou insuficientemente automatizados da formação de decisões jurídicas. Também se temem perdas relativas à possibilidade de uma diferenciação contextual na solução de problemas de cunho jurídico, bem como riscos de uma discriminação encoberta. Um tema à parte é constituído pelo risco da ocultação da imputabilidade de decisões. ${ }^{14}$ Discutem-se, além disso, consequências sociopolíticas, incluindo a eliminação de postos de trabalho

Contracts. ZfIR, 2017. p. 600; KAULARTZ. Rechtliche Grenzen bei der Gestaltung von Smart Contracts. In: TAEGER (Ed.). Smart World - Smart Law? Weltweite Netze mit regionaler Regulierung. Edewecht: OIWIR Verlag, 2016. p. 1023 ss.; FRIES (Ed.). Smart Contracts: Schlaue Verträge? [s.I.]: [s.n.], 2018.

10 Quanto a ele, veja, pars pro toto, BUNDESREGIERUNG. Digitale Verwaltung. Berlim: BT-Drucks, 2014; SENAT DER FREIEN UND HANSESTADT HAMBURG. Digital First - Chancen der Digitalisierung für eine bürgerfreundliche und moderne Verwaltung nutzen - Erweiterung der Strategie Digitale Verwaltung, Senatsdrucksache 2016/03060, 11.10.2016.

11 Quanto a essa figura, veja MÜLLER-HENGSTENBERG; KIRN. Rechtliche Risiken autonomer und vernetzter Systeme. Berlim: Walter de Gruyter, 2016. p. 59 ss.

12 Veja, p. ex., BOEHME-NEßLER, Volker. Die Macht der Algorithmen und die Ohnmacht des Rechts: Wie die Digitalisierung das Recht relativiert. NJW, 2017. p. 3035 ss.

13 Exemplos em HARTUNG. Gedanken zu Legal Tech und Digitalisierung. In: HARTUNG; BUES; HALBLEIB (Ed.). Legal Tech: Die Digitalisierung des Rechtsmarkts. Munich: C.H.Beck, 2018. p. 10 ss.

14 Quanto a isso, veja WISCHMEYER. Regulierung intelligenter Systeme. AöR, v. 143, n. 1, 2018. p. 18 ss.; 42 ss. 
especialmente nas profissões ligadas à consultoria jurídica; a isso se associa o prognóstico de uma concentração de atividades particularmente lucrativas nos grandes escritórios de advocacia ${ }^{15}$ e, na sequência, a redução de escritórios menores ou de porte médio.

\subsection{Delimitação do tema}

As reflexões que se seguem abordam apenas um recorte de possíveis áreas de problemas. No centro se encontra, após observações introdutórias sobre pressupostos selecionados da transformação digital (2, 3), a questão - importante para um Estado de Direito - de até que ponto, na ampliação da digitalização, especialmente na utilização de sistemas algorítmicos aprendentes/inteligentes, surgem mudanças na qualidade do direito e em sua aplicação, incluindo a efetivação do direito $(4,5)$. Com isso também se tematizam necessariamente questões da legitimação democrática, particularmente na medida em que esta última deve se realizar por meio da vinculação dos tomadores de decisão à lei democrática e da transparência e do controle do processo de tomada de decisão e das razões da decisão (6). A exposição faz referência a dois campos exemplares: o da tomada automatizada de decisões juridicamente relevantes bem como o da implementação automatizada de normas jurídicas $(7,8)$. Na conclusão, destacase a regulação baseada em algoritmos como modo específico de governança (9).

\section{Sistemas inteligentes baseados em algoritmos}

O ponto de partida da transformação digital é a utilização de algoritmos digitais. ${ }^{16}$ Estes são regras formuladas em uma linguagem (digital) que pode ser lida por computadores e que cumprem determinadas tarefas basicamente em passos fixos (neste sentido, de modo determinístico). Na medida em que eles não fazem isso exclusivamente segundo um padrão determinado e, na sequência, com a ajuda de passos decisórios preestabelecidos, também desenvolvem seus programas por conta própria, diz-se que são algoritmos aprendentes.

15 WENZLER. Big Law \& Big Tech. In: HARTUNG; BUES; HALBLEIB (Ed.). Legal Tech: Die Digitalisierung des Rechtsmarkts. Munich: C.H.Beck, 2018. p. 77 ss.

16 Quanto a mais detalhes sobre eles, WISCHMEYER. Regulierung intelligenter Systeme. AöR, v. 143, n. 1, 2018. p. 10 ss.; VON BÜNAU. In: BREIDENBACH; GLATZ (Ed.). Rechtshandbuch Legal Tech. Munich: C.H.Beck, 2018. p. 48. Uma análise crítica das diversas funções dos algoritmos é empreendida por KITCHIN. Thinking Critically about and Researching Algorithms. Information, Communication \& Society, 2016. p. 1 ss. 
As capacidades especiais desses algoritmos se baseiam particularmente no emprego de uma inteligência artificial apropriada para isso,$-{ }^{17}$ portanto, não de uma inteligência humana, e sim construída tecnologicamente. Com a ajuda dela se simulam, p. ex., da forma mais ampla possível, estilos de pensamento e regras de ação humanas. Também se tenta criar redes neuronais “artificiais”, ou seja, redes que copiam o processo humano de tomada de decisões apoiado em neurônios.

Sistemas inteligentes que também utilizam inteligência artificial (IA) na forma em que se manifesta no aprendizado de máquina ${ }^{18}$ têm particularmente a capacidade de reconhecer padrões, avaliar imagens, traduzir linguagem para textos, gerar regras ou elaborar prognósticos. Sistemas inteligentes especialmente "vigorosos" podem se adaptar por conta própria a novos problemas ou situações e têm condições de continuar escrevendo os próprios programas e, neste sentido, desenvolver-se independentemente da programação humana. Com referência a isso, algumas pessoas usam o termo Deep Learning, ${ }^{19}$ e outras falam de sistemas autônomos ou complexos. ${ }^{20}$ Esses sistemas conseguem aprender sem intervenções humanas adicionais. Em especial, podem captar por conta própria nexos, estruturas e arquiteturas e, da mesma forma, melhorar sua performance com base nas novas informações que absorvem. Podem agir de modo reativo e proativo e interagir com outros sistemas. Embora o desenvolvimento de tais sistemas aprendentes exija programações humanas no ponto de partida, estão projetados para tornar a influência humana tão dispensável quanto possível no desenvolvimento ulterior do software.

Por isso, em sistemas aprendentes, os fatores que se tornam determinantes para a definição de decisões e a interação deles, bem como a lógica utilizada para isso, só são compreensíveis ou transparentes de maneira limitada ou nem o são mais para os programadores e as programadoras - e muito menos para os usuários dos programas. Por ocasião da programação humana e do tratamento

17 Quanto a ela, veja, em termos gerais, RUSSELL; NORVIG. Künstliche Intelligenz. 3. ed. Munich: Pearson Studium, 2012; R REICHWALD; PFISTERER. Autonomie und Intelligenz im Internet der Dinge. CR, 2016. p. 2008 ss.; ERTEL, Wolfgang. Grundkurs Künstliche Intelligenz. 4. ed. New York: Springer, 2016; ALPAYDIN, Ethem. Machine learning. Cambridge: MIT Press, 2016; BITKOM. Künstliche Intelligenz verstehen als Automation des Entscheidens. Berlin: Bitkom, 2017. Disponível em: https://www.bitkom.org/Bitkom/ Publikationen/Kuenstliche-Intelligenz-verstehen-als-Automation-des-Entscheidens.html. Acesso em: 31 maio 2018.

18 Quanto a ele e sua aplicação no âmbito jurídico, veja SURDIN. Machine Learning and Law. Washington Law Review, v. 89, 2014. p. 87 ss.

19 Quanto a isso, veja GOODFELLOW; BENGIO; COURVILLE. Deep Learning. Cambridge: MIT Press, 2016; STALDER, Felix. Kultur der Digitalität. Berlim: Suhrkamp Verlag AG, 2016. p. 177 ss.; MÜLLERHENGSTENBERG; KIRN. Intelligente "Software-Agenten": Eine neue Herausforderung für unser Rechtssystem? Multimedia \& Recht, 2014. p. 307 ss.

20 Esse é o caso de PIEPER. Die Vernetzung autonomer Systeme im Kontext von Vertrag und Haftung. InTeR, 2016. p. 188; 190 ss.; WISCHMEYER. Regulierung intelligenter Systeme. AöR, v. 143, n. 1, 2018. 
de dados como input, o grau de responsabilidade humana ainda é relativamente alto, mas diminui no transcurso do aprendizado automático das máquinas e na aplicação do que foi aprendido.

Com isso, surgem, como consequência, problemas consideráveis, p. ex., limitações de responsabilidade, explicabilidade, possibilidade de fundamentação, previsibilidade e transparência, bem como de supervisão e controle humano ou até das possibilidades de medidas contrárias no caso de ocorrerem desenvolvimentos errados. $^{21}$

\section{Um caso especial: a utilização de big data ${ }^{22}$}

Um pressuposto importante para a efetividade de sistemas baseados em algoritmos, particularmente de sistemas aprendentes, é a disponibilidade de uma grande quantidade de dados qualitativamente tão valiosos quanto possível e utilizáveis em grande velocidade e com possibilidades diversificadas de agrupamento e avaliação, ou seja: de big data. Na ciência da informação, esses dados são entendidos como sinais ou símbolos formalizáveis e transportáveis para mensagens. Como tais, os próprios dados não possuem significado, mas eles são portadores de informações ("dados percebidos semanticamente") ${ }^{23}$ e, neste sentido, matéria-prima para usos comunicacionais.

21 Independentemente do problema específico do emprego de inteligência artificial na criação e aplicação do direito, recentemente têm aumentado as advertências quanto ao risco do emprego ilimitado da inteligência artificial. Entre os críticos também se encontram alguns atores que, ao longo de sua história de vida, impulsionaram o desenvolvimento da IA e a utilizaram em seus negócios, como ex., o cofundador da PayPal e proprietário da Tesla, Elon Musk, o fundador da Microsoft, Bill Gates, ou o cofundador da Apple, Steve Wozniak. Referências se encontram, entre outros, em SCHERER. Regulating Artificial Intelligence Systems: Risks, Challenges, Competencies, and Strategies. Harvard Journal of Law \& Technology, v. 29, 2016. p. 353; 355. Veja também os trabalhos escritos em estilo deliberadamente alarmante de BOSTROM, Nick. Superintelligence: Paths, Dangers, Strategies. Oxford: OUP Oxford, 2013; e TEGMARK, Max. Life 3.0: Being Human in the Age of Artificial Intelligence. New York: Knopf, 2017. Alertas também são emitidos por HAWKING, Stephen. Kurze Antworten auf große Fragen. 4. ed. Stuttgart: Klett-Cotta, 2018. p. 209 ss.; 213 ss. Também autoridades públicas tiveram sua atenção despertada e ao menos encaminharam processos de observação e análise da evolução dos acontecimentos. Não entraremos aqui nessa problemática fundamental.

22 Quanto a big data em termos gerais, veja MAYER-SCHÖNBERGER; CUKIER. Big data. A Revolution That Will Transform How We Live, Work and Think. Boston: Houghton Mifflin Harcourt, 2013; TAEGER (Ed.). Big data \& Co: Neue Herausforderungen für das Informationsrecht. Edewecht: OIWIR Verlag, 2014; SÆETMAN; SCHNEIDER; GREEN (Ed.). The Politics of big data: big data, Big Brother? Abingdon: Routledge, 2018 apud KOLANY-RAISER; HEIL; ORVAT; HOEREN (Ed.). Big data und Gesellschaft: Eine multidisziplinäre Annäherung. New York: Springer VS, 2018; HOFFMANN-RIEM (Ed.). Big data: Regulative Herausforderungen. BadenBaden: Verlagsgesellschaft, 2018.

23 A formulação é de WIEGERLING. Daten, Informationen, Wissen. In: BREIDENBACH; GLATZ (Ed.). Rechtshandbuch Legal Tech. Munich: C.H.Beck, 2018. p. 20. 
Para o processo da transformação digital é significativo o fato de que os computadores conseguem armazenar e utilizar sem perdas um número consideravelmente maior de dados do que os seres humanos com sua memória limitada. Os computadores também estão, em princípio, em condições de avaliar dados de modo muito mais rápido do que os seres humanos. Entretanto, conhecimentos sobre nexos só são - ao menos até agora - possíveis na forma de correlações estatisticamente significativas entre fatores diversos. Com base nelas não se podem constatar causalidades, mas é possível supô-las com determinada probabilidade. 0 mesmo - a confiança em correlações - se aplica à previsão de decisões futuras ou, de modo mais geral, de desdobramentos futuros. Devese acrescentar, contudo, que também os seres humanos nem sempre podem recorrer a constatações causais e dependem de suposições subsidiárias, p. ex., recorrendo a estimativas ou heurísticas.

\subsection{Analítica de big data}

Diversas espécies de analítica que também podem recorrer à inteligência artificial estão disponíveis para a avaliação e utilização de big data, especialmente: 1) Com a ajuda da analítica descritiva de big data se faz a triagem e o tratamento de dados; eles são, p. ex., priorizados, classificados ou filtrados para fins de avaliação. Esta pode ser usada, p. ex., para pesquisas, listagens, sistematizações (entre outras coisas) de regulações jurídicas e outros materiais de relevância para o direito. 2) A analítica preditiva de big data visa especialmente identificar as correlações já mencionadas. 0 objetivo é, p. ex., obter percepções sobre o comportamento humano, conhecer tendências e padrões de comportamento que estão se desenvolvendo e prever o comportamento. Um exemplo proeminente disso é o chamado Predictive Policing (Policiamento Preditivo). ${ }^{24}$ A analítica preditiva pode ser bastante útil para uma criação e aplicação do direito orientada pelos efeitos e para uma ciência jurídica interessada nas consequências. ${ }^{25}$ Ela também é aproveitada para prever decisões judiciais ou administrativas por meio da avaliação de decisões anteriores. 3) Com a ajuda da analítica prescritiva de big data podem-se formular recomendações de ações, p. ex., como estratégias e táticas visando influenciar posturas e comportamentos, ou para a seleção

24 Quanto a isso, veja GLESS. Predictive Policing und operative Verbrechensbekämpfung. In: HERZOG; SCHLOTHAUER; WOHLERS (Ed.). Rechtsstaatlicher Strafprozess und Bürgerrechte. Berlim: Duncker \& Humblot GmbH, 2016. p. 165 ss.; EGBERT. Siegeszug der Algorithmen? APuZ, n. 32/33, 2017; RADEMACHER. Predictive Policing im deutschen Polizeirecht. AöR, v. 142, 2017. p. 366 ss.

25 Quanto a ela, veja HOFFMANN-RIEM. Wirkungsorientierte Rechtswissenschaft. ZfRSoz, 2018. p. 20 ss. 
personalizada na oferta de prestações ou serviços. Esses dados também podem ser empregados no desenvolvimento de critérios para a intensificação de atividades da polícia judiciária em áreas definidas como tendentes a riscos, baseando-se, $p$. ex., nos resultados do Predictive Policing. Os resultados da avaliação de grandes quantidades de dados por meio desses tipos de analítica podem ser inseridos de forma automatizada nos sistemas algorítmicos concebidos para decisões e melhorar o funcionamento e desempenho de sistemas aprendentes, em especial. Eles podem, ao mesmo tempo, condicionar as decisões em casos avulsos concretos.

\subsection{Um caso especial: garantia da qualidade}

O proveito de processos digitais, incluindo a analítica de big data e a implementação de conhecimentos em decisões relevantes para o direito, depende fortemente da qualidade do software que serve de apoio para o processamento bem como dos dados utilizados.

Existem muitos critérios de qualidade. Mencionamos apenas alguns. Da qualidade dos dados fazem parte, p. ex., a integridade e disponibilidade, bem como, eventualmente, a preservação da confidencialidade dos dados. Essas qualidades não são asseguradas automaticamente, mas necessitam de cultivo e controle. A qualidade dos dados pode sofrer pelo fato de ficarem ultrapassados ou por causa de mudanças jurídicas, por exemplo.

Problemas de segurança também fazem parte dos riscos de qualidade para dados e software. Esses problemas podem estar associados ao fato de aplicativos serem usados recorrendo a nuvens externas e de suas respectivas infraestruturas de nuvem que se encontram na esfera de responsabilidade de outras empresas, onde podem se tornar vulneráveis a intervenções de terceiros. Esse é um exemplo dos muitos desafios que se colocam na produção da segurança dos dados. ${ }^{26}$

Problemas de qualidade também podem surgir pelo fato de programas digitais serem produzidos por divisão de trabalho, sem que as respectivas partes e seus efeitos de controle sejam concretamente atribuíveis e sem que os participantes reconheçam sempre quais consequências de programação são produzidas pela ação de quais atores e até que ponto eles são mutuamente compatíveis. Também se deve pressupor, via de regra, que no design de hardware e software sejam

26 Quanto aos problemas de modo geral, veja WISCHMEYER. Informationssicherheitsrecht: ITSicherheitsgesetz und NIS-Richtlinie als Bausteine eines Ordnungsrechts für die Informationsgesellschaft. Die Verwaltung, v. 50, 2017. p. 155 ss. 
utilizados componentes produzidos por outros e cujos efeitos resultantes da programação eventualmente não possam ser integralmente percebidos, de modo que possam, p. ex., desencadear o risco de programas serem concebidos de forma disfuncional.

Do ponto de vista jurídico, faz parte da qualidade do software especialmente que a programação leve em consideração todos os fatores juridicamente determinantes e exclua fatores normativamente indesejáveis como, p. ex., motivos inadmissiveis ou valorações contrárias às normas. Por exemplo: parâmetros discriminatórios ou voltados à manipulação não podem estar embutidos no design do sistema algorítmico. ${ }^{27}$

\section{Funções do direito}

Como se mencionou no início, tecnologias digitais são empregadas em muitos setores da sociedade e acarretam desafios próprios em cada caso. Esta contribuição trata especialmente dos desafios a serem enfrentados no ordenamento jurídico. Para compreendê-los, faz sentido focar inicialmente em funções importantes do direito nas sociedades modernas.

As normas jurídicas contêm prescrições sobre o que se pode fazer, sobre o que se deve fazer, mas também sobre o que é proibido fazer. Com isso, elas criam regras para a estruturação da convivência social e, ao mesmo tempo, para o enfrentamento de problemas, p. ex. para a solução de conflitos. Por meio do direito também se criam instituições e se estabelecem estruturas. Entre as funções do direito se encontram também a limitação do uso do poder e particularmente a proteção contra o abuso de poder.

Por causa da transformação digital, a problemática do poder adquiriu novas dimensões em muitas áreas. Assim, a digitalização e, junto com ela, a utilização de big data usando inteligência artificial permitem novas formas e conteúdos da geração e utilização de conhecimento, bem como possibilidades de acumulação de conhecimento. A articulação de campos de atividade diversificados é facilitada. Também surgem novas possibilidades de vigilância estatal e privada. ${ }^{28}$ A digitalização cria uma série de novas possibilidades de aquisição e aumento de poder econômico e político ${ }^{29}$ e, junto com elas, também a possibilidade de

27 Veja, p. ex., BOTZDAG. Bias in Algorithm Filtering and Personalization. Ethics and Information Technology, v. 15, 2013. p. 209 passim; TENE; POLONETSKY. Big data for All. Northwestern Journal of Technology and Intellectual Property, v. 11, 2013. p. 239 passim.

28 A questão da vigilância não será aprofundada neste trabalho.

29 HOFFMANN-RIEM. Rechtliche Rahmenbedingungen für und regulative Herausforderungen durch big data. In: HOFFMANN-RIEM (Ed.). Big data: Regulative Herausforderungen. Baden-Baden: Verlagsgesellschaft, 2018. p. 11; 38 ss. 
influenciar posturas, valores e experiências de pessoas. Algo que merece atenção jurídica especial são medidas de controle do comportamento, ${ }^{30}$ particularmente aquelas cujas prescrições não são conhecidas das pessoas atingidas ou só o são em grau limitado; trata-se, portanto, de medidas que as tornam objetos de controle inconsciente ${ }^{31}$ de modo que a autonomia comportamental delas fica ameaçada.

Tanto normas jurídicas oriundas das autoridades públicas quanto regras jurídicas estabelecidas privadamente podem fazer uso de tecnologias digitais e influenciar o desenvolvimento da digitalização na sociedade. Exemplos de direito oriundo do Estado se encontram nas normas de proteção de dados. Exemplos de regras privadas são códigos de conduta. Um direito não estabelecido pelas autoridades - mas eventualmente objeto de "cuidado zeloso" por meio de normas estabelecidas pelo Estado - existe também em esferas da sociedade relacionadas com a comunicação digital. Exemplos disso são também as prescrições criadas pelos chamados intermediários da informação - como, p. ex., Google ou Facebook - ou por outras empresas, em geral juridicizadas mediante sua inclusão em termos e condições gerais, sobre as relações comerciais com os usuários e, particularmente, sobre o processamento dos dados produzidos no marco dessas atividades. Outro exemplo é o chamado direito da PayPal, ${ }^{32}$ do qual faz parte o conjunto de regras emitido pela PayPal como diretriz para a proteção do vendedor, que, em grande parte, é implementado de forma amplamente automatizada.

\section{Garantia de vinculação às regras em forma de construtos sociais e tecnológicos}

Tanto a criação do direito quanto sua aplicação quando de um ensejo concreto - p. ex., quando de uma decisão em um conflito - foram durante muito tempo e, em grande parte, continuam sendo decisões "feitas por mão humana". Estas últimas podem ser entendidas como construtos sociais criados em determinados contextos. $^{33} \mathrm{Na}$ medida em que se empregam algoritmos como complemento

Mois detalhes quanto a ele em JUST; LATZER. Governance by Algorithms: Reality Construction by Algorithmic Selection on the Internet. Media, Culture \& Society, v. 29, 2016; HOFFMANN-RIEM. Verhaltenssteuerung durch Algorithmen - eine Herausforderung für das Recht. AöR, v. 142, 2017. p. 2 ss. Veja também BUCHHOLTZ, Gabriele. Legal Tech: Chancen und Risiken der digitalen Rechtsanwendung. JuS, 2017. p. 955 ss.

31 Quanto a isso, veja HILDEBRANDT. Law as Computation in the Era of Artificial Legal Intelligence: Speaking Law to the Power of Statistics. University of Toronto Law Journal, v. 68, 2018. p. 12 ss.

32 Quanto a isso, veja FRIES, Martin. PayPal Law und Legal Tech - was macht die Digitalisierung mit dem Privatrecht? NJW, 2016. p. 2860 ss.

33 Mais detalhes em HOFFMANN-RIEM. Verhaltenssteuerung durch Algorithmen - eine Herausforderung für das Recht. $A \ddot{R}$, v. 142, 2017. p. 26 ss. 
para a formação de decisões, estas últimas são, via de regra, produto de uma combinação de construtos sociais e tecnológicos. Trata-se de construtos sociais na medida em que os algoritmos, ao menos no ponto de partida, baseiam-se em uma programação humana. Esta pode provir de um indivíduo ou - como ocorre frequentemente - estar inserida em processos complexos de desenvolvimento de softwares com a participação de várias pessoas. Até mesmo algoritmos aprendentes com um alto grau de desenvolvimento precisam, inicialmente, ser programados por seres humanos antes de poderem se programar por conta própria.

Também há atos de conformação social quando se integram experiências, objetivos e valorações em programas de software e se levam em consideração possíveis consequências das decisões a serem tomadas. Os parâmetros determinantes para isso são inseridos na tecnologia por pessoas no decurso da programação baseada em algoritmos para utilização descontextualizada e podem, na sequência, ser empregados de forma puramente tecnológica.

$\mathrm{Na}$ aplicação de algoritmos assim criados, o fator humano pode permanecer, dentro de certos limites, relevante para as decisões. Isto ocorre, em todo caso, na medida em que a solução de problemas concretos depende de informações que não são geradas tecnologicamente, mas são disponibilizadas por seres humanos como input - p. ex., os fatos como fundamento de uma decisão jurídica. ${ }^{34}$ Neste marco, por meio da disponibilização de input pode ocorrer uma nova contextualização, a saber, um direcionamento da decisão a ser tomada para os respectivos problemas concretos com contextos específicos em cada caso.

O processamento do input por meio de utilização exclusiva dos algoritmos é um processo exclusivamente tecnológico. Este se distingue de decisões humanas em vários sentidos - ${ }^{35}$ mesmo que o desenvolvimento, em especial, de redes neuronais venha a possibilitar adaptações no futuro. Sobre o estado de coisas atual, observa-se apenas o seguinte: particularmente importante é o fato de que os algoritmos, segundo suas possibilidades e funções tecnológicas atuais, não dispõem de algumas das capacidades importantes para a ação de pessoas físicas ou típicas em interações entre elas, também no caso de atos de aplicação do direito. Assim, falta-lhes a capacidade para a utilização do conhecimento implícito, importante para a ação humana, bem como a capacidade para a empatia, para o desenvolvimento de criatividade ou para o emprego da intuição ou - importante

34 o §24, 1 do Código do Processo Administrativo, p. ex., reconhece que fatos também podem ser levantados eletronicamente. Quanto a isso, veja também BERGER, Ariane. Der automatisierte Verwaltungsakt. NVwZ, 2018. p. $1260 ; 1263$ ss.

35 Mais detalhes em HOFFMANN-RIEM. Verhaltenssteuerung durch Algorithmen - eine Herausforderung für das Recht. $A \ddot{R} R$, v. 142, 2017. p. 25 ss. 
para juristas - avaliação judicial intuitiva. Também no caso da interpretação de sentido $^{36}$ orientada por argumentos, importante para a interpretação de normas, os algoritmos topam com limites - ao menos até agora. Ao menos limitada é, além disso, a capacidade de fazer ponderações complexas ajustando os critérios da ponderação ao respectivo contexto e a correlação deles.

Essas deficiências não podem ser eliminadas atualmente, mas em muitos casos decerto é possível ocultá-las mediante simulação e pela utilização de correlações apuradas com procedimentos estatísticos. ${ }^{37}$ Entretanto, o emprego dos procedimentos típicos de uma série de medidas da criação e aplicação do direito não pode ser "reconstruído" identicamente em termos de conteúdo por computadores. Isso diz respeito, p. ex., ao caráter determinante de uma deliberação coletiva, que muitas vezes apresenta características de dinâmica de grupo, ou a negociação cooperativa de soluções que levem (ou devam/possam levar) a uma otimização dos interesses em jogo, também a partir da perspectiva individual das pessoas envolvidas.

Entretanto, à solução de problemas com recursos tecnológicos também estão associadas vantagens consideráveis, p. ex., no tocante à rapidez e à redução de custos de decisões ou ao maior número e diversidade de fatores passíveis de processamento. Mencione-se também a possibilidade de evitar a influência de preferências e preconceitos subjetivos normativamente indesejáveis dos indivíduos que tomam as decisões e de excluir motivos juridicamente inadmissíveis, mas não tematizados pelos tomadores de decisões, p. ex., uma discriminação encoberta. Se, contudo, predeterminações normativamente indesejáveis estiverem inseridas no software utilizado para o controle jurídico, elas também podem se tornar atuantes em decisões automatizadas. ${ }^{38}$

\section{Requisitos de legitimação}

No exercício de influência sobre o comportamento ou, de modo mais geral, sobre a evolução da sociedade com a ajuda de tecnologias digitais, a garantia

36 Quanto a isso, veja HILDEBRANDT. Law as Computation in the Era of Artificial Legal Intelligence: Speaking Law to the Power of Statistics. University of Toronto Law Journal, v. 68, 2018. p. 12 ss. Ela aponta, com razão, para a mutabilidade do conteúdo da norma em reação a condições ou suposições nas quais a norma se baseia (em minhas próprias palavras: mudanças das premissas empíricas e prescritivas da norma).

37 Mais detalhes quanto a isso em HILDEBRANDT. Law as Computation in the Era of Artificial Legal Intelligence: Speaking Law to the Power of Statistics. University of Toronto Law Journal, v. 68, 2018. p. 12.

38 Pars pro toto, TISCHBIREK. Al and Discrimination: Discriminating against Discriminatory Systems. In: RADEMACHER; WISCHMEYER (Ed.). Regulating Artificial Intelligence. New York: Springer, 2019. 
de legitimidade no tocante à democracia e ao Estado de Direito é importante, ao lado de outros fatores a serem considerados. Essa tarefa se coloca, por um lado, quando procedimentos decisórios baseados em algoritmos são usados por atores estatais. Questões de legitimação também podem, contudo, referir-se à ação de atores privados, na medida em que devem observar vinculações jurídicas e, particularmente, quando dispõem de um poder funcionalmente comparável à posição de atores estatais. A necessidade de considerar requisitos de legitimação pode ser, especialmente, uma consequência do efeito de direitos fundamentais em relação a terceiros ou em relação horizontal ${ }^{39}$ e das normas do respectivo ordenamento jurídico criadas para sua implementação.

Além da legitimação fática - o reconhecimento do exercício de poder como justo - em um Estado Democrático de Direito, a legitimação normativa também é importante..$^{40}$ Isto se refere ao exercício do poder com vinculação às prescrições jurídicas justificadas pelo legislador e a outras determinações institucionais de caráter geral, especialmente às estruturas regulatórias ${ }^{41}$ decisivas para isso e muitas vezes complexas, que podem se condensar em regimes regulatórios. O que também faz parte da legitimação normativa é a observância de princípios jurídicos gerais, em especial os que podem ser derivados das disposições sobre o objetivo do Estado (p. ex., o art. 20 da Lei Fundamental), que contêm orientações para partes consideráveis do ordenamento jurídico. Mas também outras normas constitucionais - particularmente os direitos fundamentais - proporcionam componentes legitimatórios, possibilitando, p. ex., a autonomia. ${ }^{42}$

Um fator central para assegurar a legitimação normativa é a vinculação às leis (a legalidade). Em princípio, é possivel traduzir regras jurídicas em regras técnicas. Para isso, porém, são necessárias padronizações, pois a ação por meio de computadores pressupõe ordens linguísticas inequívocas. Essas padronizações não são juridicamente problemáticas para a programação de decisões automatizadas quando se tratar da aplicação de normas passíveis de subsunção

39 Quanto a essa construção, veja BVerfGE, 7, 198, 203 ss., BVerfG (1BvR 3080/09), NJW, 2485, 2486, 2015. Entre a literatura, veja, pars pro toto, PAPIER. In: MERTEN; PAPIER (Ed.). Grundrechte in Deutschland: Allgemeine Lehren I. Munich: C.H.Beck, 2006. p. 1331-1362.

40 Quanto às dimensões da legitimação, veja, pars pro toto, TRUTE. In: HOFFMANN-RIEM; SCHMIDT-AßMANN; VOßKUHLE (Ed.). Grundlagen des Verwaltungsrechts. 2. ed. Munich: C.H.Beck 2012, §6, com referências adicionais no no 3 e na nota 10; SCHLIESKY, Utz. Souveränität und Legitimität von Herrschaftsgewalt. Heidelberg: Mohr Siebeck, 2004; WESTERMANN, Eike. Legitimation im europäischen Regulierungsverbund. Heidelberg: Mohr Siebeck, 2017, 2. Teil.

41 Quanto a esse conceito, veja HOFFMANN-RIEM. Innovation und Recht. Recht und Innovation. Heidelberg: Mohr Siebeck, 2016. p. 9 ss.

42 Quanto ao significado da autonomia em diversas áreas, veja os ensaios contidos em BUMKE; RÖTHEL (Ed.). Autonomie im Recht: Gegenwartsdebatten über einen rechtlichen Grundbegriff. Heidelberg: Mohr Siebeck, 2017. 
com prescrições inequívocas também para consequências a serem buscadas e na medida em que também os fatos aplicáveis possam ser apreendidos inequivocamente por meios digitais. Também é útil, neste sentido, que as normas jurídicas estejam configuradas condicionalmente, ou seja, como relações do tipo "se ..., então".

Entretanto, só em casos excepcionais se pode tomar a inequivocidade das predeterminações normativas como ponto de partida. ${ }^{43}$ Falta inequivocidade especialmente no caso da utilização de termos jurídicos indeterminados, de autorizações para o exercício de poder discricionário, para a feitura de prognósticos ou para o planejamento de estruturas futuras. 0 mesmo se aplica aos casos em que a norma exige ponderações, p. ex., na esteira do emprego do princípio de proporcionalidade. Neste sentido, lidar com situações conflituosas multipolares ou multiestruturais produz desafios especiais.

Falta inequivocidade também no caso de normalizações configuradas de modo finalístico, ou seja, que determinam objetivos e finalidades, mas não - ou apenas em parte - os meios admissíveis para sua realização. 0 mesmo se aplica a decisões em que a escolha de uma consequência jurídica depende de situações de risco a serem ponderadas de maneira diferente em cada caso. Um exemplo disso são os limiares de intervenção no direito da segurança interna, que precisam ou podem ser concretizados de forma diversa dependendo do valor do bem protegido por lei que está em jogo. Neste caso se tornam necessárias, do ponto de vista jurídico, constatações do tipo "quanto mais/menos ... tanto..." 44 ("Quanto maior o peso do bem protegido por lei que está ameaçado, tanto menores podem ser os requisitos de probabilidade de um dano ou prejuízo iminente"). Na maioria das vezes, também não estão inequivocamente determinadas as decisões a serem tomadas nas chamadas situações dilemáticas, ou seja, situações em que cada uma das decisões alternativas disponíveis acarreta dano ou prejuízo. A forma de lidar com situações desse tipo está sendo discutida de maneira intensiva atualmente em relação à condução autônoma de veículos, p. ex. ${ }^{45}$

Possibilidades de padronização também ficam em grande parte excluídas na medida em que normas exigem de quem toma as decisões que elas sejam tomadas

43 Quanto a isso, veja HOFFMANN-RIEM. Innovation und Recht: Recht und Innovation. Heidelberg: Mohr Siebeck, 2016. p. 80 ss.; KUNTZ. Recht als Gegenstand der Rechtswissenschaft und performative Rechtserzeugung. $A c P, 2016$. p. 866 ss., com referências adicionais.

44 Quanto a essa problemática, veja POSCHER. Eingriffsschwellen im Recht der inneren Sicherheit. Die Verwaltung, v. 41, 2008. p. 345 ss. Exemplos de fórmulas do tipo "quanto mais/menos ... tanto" em KLATT; SCHMIDT. Spielräume im öffentlichen Recht. Heidelberg: Mohr Siebeck, 2010. p. 89 ss.

45 Quanto a isso, cf., p. ex., WEBER. Dilemmasituationen beim autonomen Fahren. NZV, 2016. p. 249 ss.; BUNDESMINISTERIUM FÜR VERKEHR UND DIGITALE INFRASTRUKTUR. Ethik-Kommission automatisiertes und vernetztes Fahren. Berlim: BMVI, 2017. p. 16. 
assumindo responsabilidade individual e também incluindo fatores subjetivos, $\mathrm{p}$. ex. no tocante à avaliação do descumprimento de deveres de diligência e de critérios de culpa a ele relacionados ( $p$. ex., negligência ou imprudência) ou - no direito penal - na decisão sobre o montante adequado da pena ou sobre o prognóstico do risco de reincidência no caso de infratores. 0 mesmo se aplica à suposição de que um fato em que se baseia a aplicação do direito seja "verdadeiro": neste sentido, a decisão depende da convicção de quem toma a decisão (veja, p. ex., expressamente $\S 108,1$, 2 do Código de Jurisdição Administrativa e implicitamente $\S 24,1,2$ do Código de Procedimento Administrativo), ${ }^{46}$ isto é, de uma decisão a ser indubitavelmente tomada de maneira subjetiva.

Nos contextos mencionados, mas também em outros, a forma de lidar com o direito está marcada por contingências. Estas podem fazer com que se fixe um corredor limitante para decisões juridicamente defensáveis, mas que a escolha entre opções possiveis nesse corredor dependa de outras orientações e aclaramentos. Eventualmente, estes últimos precisam ser concretizados recorrendo a outras normas ou levando em consideração as finalidades do estabelecimento das normas - se for o caso, também em forma de critérios complementares,$-{ }^{47} \mathrm{e}$ em processos decisórios eles precisam ser aplicados de uma forma relacionada ao contexto.

A criação de espaços de opção no direito está aumentando atualmente. Ela é impulsionada especialmente pela integração europeia. O direito da UE - como mostram com particular clareza os considerandos dos regulamentos e diretivas - se caracteriza, em muitos casos, por uma abertura decisória, que é p. ex., expressão de uma solução conciliatória no estabelecimento das normas ou se deve ao fato de que os desdobramentos não eram previsíveis desde o início e, por isso, uma abertura para o futuro deveria ser assegurada pelo gênero da normalização.

Caso falte uma normalização inequívoca e passível de subsunção, isso diz respeito, obviamente, não só a decisões baseadas em algoritmos, mas também àquelas que são tomadas exclusivamente por pessoas físicas. No caso das decisões usuais até agora, tomadas por pessoas, o ordenamento jurídico contém, entretanto, uma série de disposições complementares para lidar com margens decisórias e para assegurar a qualidade decisória que se busca. Elas dizem respeito, particularmente, aos fatores de controle relativos à organização,

46 A tarefa da formação de uma convicção faz parte do princípio da livre apreciação das provas contido no Código; cf. KOPP; RAMSAUER. Verwaltungsverfahrensgesetz. 19. ed. Munich: C.H.Beck, 2018. §24, n. 11.

47 Quanto a isso, veja HOFFMANN-RIEM. Maßstabsergänzung bei der Rechtsanwendung: eine methodische Notwendigkeit. Festschrift für Hans-Joachim Koch, 2014. p. 57 ss. 
ao procedimento e aos recursos humanos e financeiros. ${ }^{48}$ Sua eficácia depende de muitos fatores distintos, p. ex., da respectiva ordem de competências e das normas organizacionais internas para fluxos de trabalho e formas de procedimentos, das culturas decisórias cultivadas na organização, das orientações (especialmente profissionais) dos recursos humanos bem como da disponibilidade de conhecimento, dinheiro e tempo. Auxílios decisórios complementares podem ser utilizáveis recorrendo-se à expertise externa, à participação dos envolvidos, à cooperação de autoridades públicas com pessoas ou instituições privadas ou ao emprego de determinadas modalidades de governança (como mercado, negociação, rede, hierarquia; v. também seção 9 a seguir). Se a possibilidade de fazer uso desses fatores de controle está legitimada no ordenamento jurídico, eles também podem ser entendidos como fatores legitimatórios complementares ao se lidar com o poder jurídico para a escolha de opções.

Em face da abertura para opções de muitas normalizações jurídicas e da consequente dependência dos demais fatores de controle mencionados, a imagem da necessidade de uma cadeia de legitimação que deveria existir entre o legislador e os operadores do direito, durante muito tempo usada pela jurisprudência e por grande parte da literatura para ilustrar uma legitimação suficiente, não é mais adequada. ${ }^{49}$ Essa imagem só consegue descrever acertadamente a existência de legitimação mediante legalidade para situações em que há prescrições inequívocas e conexões lineares entre os diversos elementos decisórios e a possibilidade de concatenações determinísticas. ${ }^{50}$ Para o ordenamento jurídico atual, contudo, essa imagem só tem ainda uma adequação limitada. 0 direito não só opera, muitas vezes, com regras decisórias contingentes, mas também encerra muitos componentes legitimatórios, que podem estar mutuamente concatenados em diversos níveis jurídicos (p. ex., direito da UE e direito nacional). Por isso, não é acaso que atualmente se esteja discutindo sobre concepções legitimatórias mais complexas. Considera-se particularmente importante a asseguração, no cômputo geral, de um "nível de legitimação adequado" 51 que possa ser alcançado através da utilização de diversos componentes legitimatórios. ${ }^{52}$ Melhor do que a metáfora da cadeia me parece ser a imagem - se é que se precisa de uma imagem - de uma

48 HOFFMANN-RIEM. Innovation und Recht. Recht und Innovation. Heidelberg: Mohr Siebeck, 2016. p. 97 ss.

49 Quanto a essa imagem (e sua adequação limitada), veja, p. ex., as palestras de KLEY; KIRSTE. Kontexte der Demokratie: Herrschaftsausübung in Arbeitsteilung. VVDStRL, v. 77, 2018. p. 125; 127 ss.; p. 161; $182 \mathrm{ss}$.

50 Neste sentido, a imagem da cadeia de legitimação vai ao encontro da utilização de algoritmos concebidos de maneira determinística.

51 Veja, p. ex., BVerfGE 83, 60, 77, 81; 107, 59, 87.

52 Quanto a isso, veja WESTERMANN, Eike. Legitimation im europäischen Regulierungsverbund. Heidelberg: Mohr Siebeck, 2017. p. 213 ss. 
rede de legitimação. Ela indica que muitas vezes existem nós e conexões diversos e "heterarquicamente" ordenados na formação de decisões. Para eles podem ser observadas disposições específicas em cada caso - também de natureza procedimental - ao se lidar com as margens decisórias dadas.

A confiança do ordenamento jurídico em fatores de controle complementares (como recursos humanos, organização ou procedimentos) se refere até agora, em grande parte, a decisões com a inclusão de pessoas físicas. Deve-se levar em consideração que há uma situação com problemas diferentes se as decisões são tomadas prioritária ou exclusivamente com base em algoritmos. 0 desenvolvimento de um programa de software voltado para isso, especialmente um programa de software que opera de modo determinístico, e sua aplicação a um processo jurídico concreto ocorrem sob condições contextuais ou marcos inteiramente diferentes da criação de uma norma jurídica e de sua aplicação em um caso específico por parte de tomadores de decisão humanos.

llustremos isso aqui a partir da fase do desenvolvimento de software. Usualmente, diversos atores tomam parte na respectiva elaboração dos requisitos para a concepção concreta da arquitetura do software, a realização técnica do processamento eletrônico de dados por meio da codificação, para os testes do software e, eventualmente, sua revisão após experiências na operação em testes ou na operação real. Esses atores de modo algum são sempre ou até apenas juristas. Os participantes são principalmente especialistas em TI. O processo de programação - ou seja, o procedimento - não está regulamentado juridicamente: até agora não existem prescrições jurídicas referentes à criação do software em termos de procedimento ou requisitos específicos para assegurar a legitimação democrática. De modo algum está assegurado que somente fatores decisórios jurídicos ou, em todo caso, juridicamente legitimados sejam inseridos na programação ou nos programas de treinamento de algoritmos aprendentes. Além disso, o processo de programação como tal não está sujeito a um controle jurídico específico.

De resto, tendo em vista a estrutura fundamentalmente determinística do modus operandi dos algoritmos e as imposições daí resultantes, é plausivel que os programadores tratem as respectivas normas como tão inequívocas quanto possível e as fixem dessa forma, mesmo que elas não o sejam. Fazendo-se isso não se observaria o fato de que os conteúdos das normas não estão fixos de uma vez para sempre. No caso da aplicação do direito, as normas necessitam, isto sim, de uma concretização contextual como direito a ser aplicado à decisão concreta (chamada de norma decisória). ${ }^{53} \mathrm{~A}$ aplicação do direito também é um

53 Quanto a essa concepção, cf. MÜLLER; CHRISTENSEN. Juristische Methodik: Grundlagen für die Arbeitsmethoden der Rechtspraxis. 11. ed. Berlim: Duncker \& Humblot GmbH, 2013, especialmente 
ato de geração do direito, um "ato performativo". ${ }^{54}$ Se a contingência do direito e necessidade de concretização contextual no ato da aplicação são negligenciados em função da natureza da programação baseada em algoritmos, surge o risco de um estreitamento e, com isso, de um retrocesso da metodologia "jurística" ou em outras palavras - a aproximação a um neopositivismo digital ${ }^{55}$ (problemático, em minha opinião).

Outro problema surge do fato de que na programação e, na sequência, também na aplicação do programa não se pode recorrer a fatores de controle do tipo soft aproveitáveis para o agir humano que - ao menos até agora - não podem ser reproduzidos em algoritmos. Isso diz respeito, p. ex. - como já se mencionou anteriormente (5) -, à utilização do conhecimento implícito, ao emprego da intuição e empatia, ao desenvolvimento de criatividade, a ponderações complexas, mas também à interpretação do significado de normas que é importante para a explicação destas e, se for o caso, reage a mudanças contínuas de premissas empíricas e prescritivas da norma.

Atualmente ainda não se pode prever se e como, com base nos desdobramentos ulteriores da IA, será possível, futuramente, moldar o processo de programação de tal maneira que também se possam criar e utilizar para ele equivalentes funcionais para a eficácia dos fatores do tipo soft mencionados, que estão vinculados aos seres humanos. Mesmo que isso não venha a ser alcançado, devese esperar, ainda assim, que vá aumentar a pressão para um maior envolvimento com a digitalização. ${ }^{56} \mathrm{~A}$ utilização de tecnologias digitais corresponde não só aos interesses das empresas ligadas à TI e dos advogados que trabalham com Legal Technology e de outros atores, mas também à programática política de muitos tomadores de decisões, p. ex., na ampliação do E-Government. Em face das muitas vantagens da digitalização deve-se esperar que, com grande probabilidade, no futuro processos baseados em algoritmos continuem a ser ampliados, tanto em setores estatais quanto privados.

n. 233, 274; HOFFMANN-RIEM. Innovation und Recht: Recht und Innovation. Heidelberg: Mohr Siebeck, 2016. p. 60 ss.; 80 ss.; KUNTZ. Recht als Gegenstand der Rechtswissenschaft und performative Rechtserzeugung. AcP, 2016. p. 867; 873 ss.

54 Quanto a isso, veja KUNTZ. Recht als Gegenstand der Rechtswissenschaft und performative Rechtserzeugung. AcP, 2016. p. 874; 876.

55 HOFFMANN-RIEM. Verhaltenssteuerung durch Algorithmen - eine Herausforderung für das Recht. AöR, v. 142, 2017. p. 17; WIEGERLING. Daten, Informationen, Wissen. In: BREIDENBACH; GLATZ (Ed.). Rechtshandbuch Legal Tech. Munich: C.H.Beck, 2018. p. 23, enxerga uma "metafísica positivista" por trás da dataficação.

56 AHRENDT, Christian. Alte Zöpfe neu geflochten. Das materielle Recht in der Hand von Programmierern. NJW, 2017. p. 537, refere-se à influência plasmadora do direito causada pela pressão para a eficiência desencadeada pela automatização. 
A exposição que se segue não trata das múltiplas possibilidades de utilização de tecnologias digitais e particularmente de Legal Tech, especialmente nos mercados de prestação de serviços jurídicos. ${ }^{57}$ Pretende-se, isto sim, apenas mostrar exemplarmente possibilidades e problemas específicos ligados a decisões baseadas em algoritmos. Para isso, escolho inicialmente a possibilidade de decisões automatizadas (7). Na sequência se segue uma exposição da efetivação automatizada do direito (8).

\section{Requisitos para decisões automatizadas ${ }^{58}$ \\ 7.1 Disposições do Regulamento Geral de Proteção de Dados da União Europeia (RGPD-UE)}

O ordenamento jurídico da UE já contém - ainda que apenas como exceção regulações especiais para decisões automatizadas. Delas fazem parte o RGPD-UE

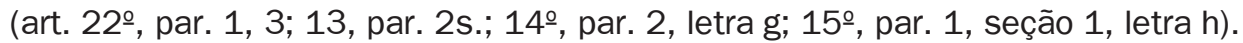
Essas regras devem ser entendidas funcionalmente como prescrições para a abertura da possibilidade de decisões automatizadas, ainda que o art. 22으, par. 1 do RGPD-UE conceda, em uma formulação negativa, às pessoas o seguinte direito: "O titular dos dados tem o direito de não ficar sujeito a nenhuma decisão tomada exclusivamente com base no tratamento automatizado, incluindo a definição de perfis, ${ }^{59}$ que produza efeitos na sua esfera jurídica ou que o afete significativamente de forma similar". Entretanto, essa proibição tem uma formulação fraca pelo fato de pressupor a automatização "exclusiva" - ou seja, sem qualquer participação humana - do processamento e, além disso, só abranger casos em que a pessoa esteja "sujeita" à decisão, ou seja, esteja exposta ela sem o concurso de sua vontade. Além disso, o par. 2 contém uma série de exceções, entre as quais

57 Quanto a isso, veja as referências nas notas 3 a 5.

58 Entre a literatura sobre tais decisões, veja BRAUN BINDER. Vollständig automatisierter Erlass eines Verwaltungsaktes und Bekanntgabe über Behördenportale. DÖV, v. 21, 2016. p. 891 ss.; BULL, Hans Peter. Der „vollständig automatisiert erlassene" Verwaltungsakt - zur Begriffsbildung und rechtlichen Einhegung von E-Government. DVBL, p. 409-417, 2017. p. 409-417; HELBICH. Rechtsfragen der „automatisierten” Ermessensausübung im Steuerrecht. DStR, 2017. p. 574 ss.; BERGER, Ariane. Der automatisierte Verwaltungsakt. NVWZ, 2018 (com mais referências na nota 8).

59 Quanto ao conceito de definição de perfis (profiling), cf. art. 4ำ, ํo 4, do RGPD-UE. Nos considerandos (no 63) se acrescenta que a restrição do art. 22으, par. 1 do RGPD-UE abrange "pelo menos" casos de definição de perfis, podendo, portanto, também dizer respeito a outras configurações (não mencionadas), p. ex., scoring (quanto à definição deste conceito e outras prescrições, veja §3 da Lei Federal de Proteção de Dados [nova]). 
se encontra o consentimento explícito da pessoa afetada. ${ }^{60}$ Como meio para a regulação sustentável de interferências automatizadas, o art. $22^{\circ}$ deve se mostrar, na prática, como uma "espada sem fio" por causa de suas restrições. ${ }^{61}$

0 art. 13을 par. 2, letra f do RGPD-UE prevê, ao menos, que se disponibilizem à pessoa afetada por uma definição decisória automatizada "informações úteis relativas à lógica subjacente, bem como à importância e às consequências previstas de tal tratamento", ou que ela possa exigi-las. No considerando 63 do RGPD-UE está previsto, entretanto, que "o segredo comercial ou a propriedade intelectual e, particularmente, o direito de autor que protege o software" não devem ser prejudicados.

O RGPD-UE visa à proteção de pessoas em relação a determinados tipos de processamento de dados por parte de órgãos públicos e não públicos. Neste sentido, decisões administrativas também são afetadas pelas regras sobre o processamento automatizado de dados. Mas o RGPD-UE não regula requisitos para decisões automatizadas de modo geral - portanto, indo além da proteção de dados -; ele também só abrange decisões incriminatórias. Além disso, deve-se levar em consideração que o RGPD-UE não abrangeu especificamente a utilização importante para a Legal Technology - de sistemas algorítmicos aprendentes. ${ }^{62}$ É duvidoso que por meio de uma interpretação do RGPD-UE se consiga enfrentar de maneira adequada os problemas a eles ligados.

\subsection{A utilização de algoritmos digitais na administração pública}

$\mathrm{Na}$ medida em que decisões automatizadas sejam tomadas pela administração, devem-se observar regras adicionais. A exposição que se segue referese a isso. Contudo, também se deve mencionar que há muito tempo algoritmos vêm sendo usados pela administração, p. ex., na pesquisa ou sistematização. Determinadas decisões da administração também são emitidas eletronicamente e enviadas por funcionários encarregados sem controle individual, p. ex., avisos de concessão de pensão ou cálculos de salários e benefícios. ${ }^{63}$ No início deste milênio,

60 A este respeito encontram-se os pontos fracos referentes ao consentimento existentes em geral no direito de proteção de dados. Quanto a isso, veja, pars pro toto, HERMSTRÜWER, Yoan. Informationelle Selbstgefährdung. Heidelberg: Mohr Siebeck, 2016. p. 165 ss. passim.

61 A expressão é de HOEREN; NIEHOFF. KI und Datenschutz - Begründungserfordernisse automatisierter Entscheidungen. Rechtswisssenschaft, 2018. p. 47; 54.

62 Também segundo HOEREN; NIEHOFF. KI und Datenschutz - Begründungserfordernisse automatisierter Entscheidungen. Rechtswisssenschaft, 2018. p. 589.

63 Quanto a isso, veja, p. ex., BULL, Hans Peter. Der „vollständig automatisiert erlassene” Verwaltungsakt - zur Begriffsbildung und rechtlichen Einhegung von E-Government. DVBL, p. 409-417, 2017. p. 409 ss., 
na Alemanha, várias regras legais novas sobre comunicação eletrônica entre a administração pública e os cidadãos foram inseridas no Código de Procedimento Administrativo (especialmente $\S \S 3 a, 37,2,3,4 ; 41,2,2$ ). Além disso, a partir de 1‥1.2017 outras normas referentes a esse assunto (em especial §§24, 1; 35a; 41, 2a do mesmo Código) entraram em vigor; regras semelhantes, ainda que levemente modificadas, foram incluídas no Código Geral dos Impostos ${ }^{64}$ e no Código de Segurança Social X. ${ }^{65}$ Também se deve remeter à lei para a promoção da administração eletrônica (Lei sobre o E-Government).

As novas regras surgidas até agora deixam claro que o legislador continua confiando prioritariamente em decisões humanas e não permite decisões automatizadas nos casos em que considera o fator humano no preenchimento de espaços de opções imprescindivel para a garantia da legitimidade. Isso pode mudar no futuro, mas é decisivo no presente.

A autorização atualmente (ainda?) determinante para atos administrativos emitidos inteiramente por dispositivos automáticos se encontra no §35a do Código de Procedimento Administrativo. ${ }^{66}$ Ela é limitada de maneira que, em primeiro lugar, essa possibilidade precisa ser admitida por uma prescrição jurídica adicional e, em segundo lugar, porque não pode haver apreciação ou discrição nem uma margem de avaliação. Esse procedimento se baseia especialmente na avaliação de que os dispositivos tecnológicos disponíveis não podem efetuar uma apreciação em sentido jurídico nem avaliar adequadamente interesses juridicamente relevantes e ponderá-los uns contra os outros. ${ }^{67}$ A exclusão da automatização afeta particularmente decisões que exigem uma avaliação complexa de um fato ou preveem um exercício de apreciação ou discrição talhada para as particularidades do caso específico. ${ }^{68}$

Entretanto, decisões automatizadas na aplicação de normas com autorizações para apreciação não devem ser excluídas quando houver o que se chama de redução da apreciação a zero ou prescrições administrativas (como autovinculação da administração) tiverem produzido uma limitação da margem de

em que também há reflexões sobre quando se pode falar da existência de uma automatização completa (410 ss.).

64 Veja especialmente $\S 155,4$, mas também $§ 149,4,3$ do Código Geral de Impostos; quanto às questões jurídicas correlatas, veja HELBICH. Rechtsfragen der „automatisierten” Ermessensausübung im Steuerrecht. DStR, 2017. p. 574 ss.; AHRENDT, Christian. Alte Zöpfe neu geflochten. Das materielle Recht in der Hand von Programmierern. NJW, 2017. p. 500; 537 ss.

65 Veja, p. ex., §431a do Código de Segurança Social X.

66 Essa norma também foi transferida - em parte de forma modificada - para os Códigos de Procedimento Administrativo dos estados.

67 Segundo PRELL. BeckOK, Verwaltungsverfahrensgesetz, 39. ed., 1.4.2018, §35a, n. 14.

68 Quanto a isso, veja STELKENS. In: STELKENS; BONK; SACHS (Ed.). Verwaltungsverfahrensgesetz. 9. ed. Munich: C.H.Beck, 2018. §35a, n. 40-43. 
manobra de modo que, independentemente da formulação ampla da norma a ser aplicada, se possa pressupor a existência de uma decisão vinculada. ${ }^{69}$

A decisão inteiramente automatizada também deve ser excluída, segundo a vontade do legislador, quando houver uma margem de avaliação. Neste ponto o legislador aceitou uma inexatidão terminológica. A partir do sentido da norma se faz referência a conceitos jurídicos indeterminados, mas, ao que tudo indica, não se visa abranger todos, pois comumente o conceito de margem de avaliação só é aplicado, como termo técnico do direito, a conceitos jurídicos indeterminados na medida em que se pode depreender da lei, mediante interpretação, que a concretização desse conceito é transferida unicamente à administração pública, de modo que se elimina a possibilidade de uma correção posterior por parte de tribunais. ${ }^{70}$ Para a pergunta a ser avaliada ex ante sobre se e até que ponto uma decisão inteiramente automática deve ser aceita sob aspectos do Estado de Direito, a rigor não pode ser decisivo se e até que ponto a aplicação de um conceito jurídico está sujeita a um controle judiciário ex post. ${ }^{71} \mathrm{O}$ que deveria ser decisivo, isto sim, é o tipo da margem de decisão admitida. Como quase todos os conceitos são indeterminados em algum sentido, o legislador queria, pela escolha das palavras, indicar, pelo visto, que a automatização é excluída só para os conceitos jurídicos indeterminados acoplados a tarefas de avaliação atribuídas unicamente à administração. Afinal, em outros casos ainda entra em cogitação a possibilidade do controle judiciário da avaliação.

A decisão inteiramente automática precisa - como se mencionou - ser admitida por uma prescrição jurídica. Por isso, o legislador pode decidir se, em face do tipo de indeterminação da normalização ou da apreciação admitida, justifica-se tomar uma decisão automatizada. A prescrição da autorização legal não exige, entretanto, segundo opinião disseminada, uma autorização expressa. Uma automatização também pode estar admitida por "prescrição jurídica" quando a interpretação da norma justifica essa possibilidade. ${ }^{72}$ Isso deveria ser afirmado, p. ex., em situações nas quais se poderia emitir uma prescrição administrativa que limite correspondentemente a margem de ação da administração pública.

Para decisões administrativas têm validade os requisitos gerais do Estado de Direito para a legitimação da ação administrativa contidos no Código de

69 Por exemplo, segundo PRELL. BeckOK, Verwaltungsverfahrensgesetz, 39. ed., 1.4.2018, n. $13-16$.

70 Neste caso se aplica a chamada teoria da autorização normativa; veja HOFFMANN-RIEM. Eigenständigkeit der Verwaltung. In: HOFFMANN-RIEM; SCHMIDT-AßMANN; VOßKUHLE (Ed.). Grundlagen des Verwaltungsrechts. 2. ed. Munich: C.H.Beck 2012, n. 78 com referências na n. 432.

71 Cf. STELKENS. In: STELKENS; BONK; SACHS (Ed.). Verwaltungsverfahrensgesetz. 9. ed. Munich: C.H.Beck, 2018. §35a, n. 44-46.

72 Esta é, em todo caso, a posição de BRAUN BINDER. Vollständig automatisierter Erlass eines Verwaltungsaktes und Bekanntgabe über Behördenportale. DÖV, v. 21, 2016. p. 891; 893. 
Procedimento Administrativo. ${ }^{73}$ Para decisões automatizadas, entretanto, esse Código previu modalidades ante as regras que estão em vigor em outros casos.

No tocante aos fatos em que a decisão deve se basear, o legislador mantém basicamente o princípio da investigação determinante de modo geral para procedimentos administrativos ( $\$ 24,1,1$ do Código de Procedimento Administrativo). A frase 3 da alínea 1 dessa norma prevê que neste caso também os fatos apurados por um dispositivo automático para a emissão de atos administrativos podem ser tomados como fundamento de decisões. Acrescenta-se, porém, que isso não é suficiente se as pessoas envolvidas tenham dado informações factuais significativas para o caso específico que não foram apuradas no procedimento automático. Estas devem ser levadas independentemente em consideração, portanto segundo a avaliação humana. Neste sentido, ocorre uma verificação (limitada) da decisão automatizada por parte de uma pessoa física. ${ }^{74}$

Dos requisitos legitimados pelo Estado de Direito e pela democracia faz parte basicamente, no procedimento administrativo, o dever de justificar e, por conseguinte, via de regra de fundamentar atos administrativos, ${ }^{75}$ também atos administrativos eletrônicos ou confirmados eletronicamente (§39, 1 do Código de Procedimento Administrativo). Contudo, uma fundamentação seria dispensável no caso de decisões automatizadas quando "não é imperativa segundo as circunstâncias do caso específico" (§39, 2, 3 do mesmo Código). Essa exceção deve entrar em cogitação, com a maior probabilidade, em ações coletivas referentes a problemas semelhantes. ${ }^{76}$

Com a ajuda de uma fundamentação se visa, comumente, cumprir diversas funções de garantia da legitimação. ${ }^{77}$ Assim, ela serve para assegurar a legitimação

73 Quanto a isso, veja o posicionamento intitulado "Stellungnahme des Beirats Verwaltungsverfahrensrecht" do Ministério do Interior sobre a admissão de atos administrativos completamente automatizados e a divulgação de atos administrativos por meio de plataformas da internet, NVwZ, p. 1114 ss., 2015; PRELL. BeckOK, Verwaltungsverfahrensgesetz, 39. ed., 1.4.2018, n. 9.

74 Neste sentido, o art. 22ํㅡ, par. 3 do RGPD-UE é mais diferenciado. Lá se prevê - mesmo que apenas para uma parte das decisões automatizadas - que "o titular dos dados [tem], designadamente, o direito de, pelo menos, obter intervenção humana por parte do responsável, manifestar o seu ponto de vista e contestar a decisão".

75 Mais detalhes quanto a isso em WISCHMEYER. Regulierung intelligenter Systeme. AöR, v. 143, n. 1, 2018. p. 54 ss., com mais referências; AHRENDT, Christian. Alte Zöpfe neu geflochten. Das materielle Recht in der Hand von Programmierern. NJW, 2017. p. 540. Quanto a outras abordagens, particularmente incluindo a utilização de IA, veja WISCHMEYER. Al and Transparency: Opening the Blackbox. In: RADEMACHER; WISCHMEYER (Ed.). Regulating Artificial Intelligence. New York: Springer, 2019, especialmente Parte 3.

76 Segundo STELKENS. In: STELKENS; BONK; SACHS (Ed.). Verwaltungsverfahrensgesetz. 9. ed. Munich: C.H.Beck, 2018. §39, n. 99.

77 Segundo STELKENS. In: STELKENS; BONK; SACHS (Ed.). Verwaltungsverfahrensgesetz. 9. ed. Munich: C.H.Beck, 2018. §39, n. 1. Além disso, pars pro toto, KISCHEL, Uwe. Die Begründung. Heidelberg: Mohr Siebeck, 2003. p. 88 ss.; CHRISTENSEN; KUDLICH. Theorie richterlichen Begründens. Berlim: Duncker \& Humblot GmbH, 2001. 
factual de ações de autoridades públicas (garantia de aceitação, pacificação etc.), mas principalmente para assegurar a legalidade da decisão e para possibilitar um controle baseado em divisão de trabalho (controle próprio da administração, controle externo por tribunais e, eventualmente, pela opinião pública, incluindo a ciência)..$^{78} \mathrm{O}$ dever de fundamentação diz respeito especialmente aos fundamentos factuais, à apreciação das provas, a explanações para assegurar a transparência ou compreensibilidade da argumentação jurídica e se estende até a exposição dos efeitos a serem esperados da decisão. Tais informações são em princípio possíveis também no caso de decisões automatizadas. Entretanto, neste caso deve haver um risco elevado de que se opere com componentes textuais préfabricados e, assim, não se levem suficientemente em conta as peculiaridades do caso particular - sua vinculação a um contexto específico. Para excluir essa possibilidade, a lei pressupõe um esclarecimento sobre se e até que ponto a fundamentação, de acordo com o §39, 2, 3 do Código de Procedimento Administrativo, é dispensável segundo as circunstâncias do caso específico. Para isso, porém, não são indicados critérios de avaliação.

Em um Estado de Direito, a possibilidade de controle judicial é particularmente importante. Segundo o art. 19으, par. 4 da Lei Fundamental, a garantia da proteção jurídica pelos tribunais também se aplica a decisões automatizadas. ${ }^{79}$ Para a proteção jurídica efetiva, não basta utilizar os algoritmos empregados para a decisão inicial também para o exame ou verificação judicial que eventualmente ocorra na sequência. Assim, até agora a decisão judicial automatizada não é admitida na Alemanha. ${ }^{80}$ A utilização dos algoritmos empregados para a decisão inicial também não faria jus a um controle judicial porque os tribunais só podem proceder a uma verificação de um ato administrativo dentro de certos limites; ${ }^{81}$ em especial, o procedimento de exame judicial não tem a forma de um procedimento para a readoção de um ato administrativo. Contudo, no exame judicial da compreensibilidade das razões pode ser imprescindivel lidar com o programa de tomada de decisões em que a administração pública se baseou. ${ }^{82}$

78 Mais detalhes sobre o requisito de fundamentação e as possibilidades de situar decisões automatizadas em nexos de fundamentação, veja WISCHMEYER. Regulierung intelligenter Systeme. AöR, v. 143, n. 1, 2018. p. 42 ss.

79 Os problemas do tipo de proteção jurídica ante decisões automatizadas quase não são tratados na literatura até agora. Reflexões sobre isso se encontram, p. ex., em HELBICH. Rechtsfragen der „automatisierten” Ermessensausübung im Steuerrecht. DStR, 2017. p. 578 ss.

80 Segundo matérias de meios de comunicação, o primeiro tribunal digital do mundo teria sido instituído na China em 2017; v. MMR-Aktuell, 2017, 395452.

81 Quanto a isso, pars pro toto, WISCHMEYER. Regulierung intelligenter Systeme. AöR, v. 143, n. $1,2018$. p. 57.

82 Quanto a essa questão existem discussões na jurisprudência e na literatura dos Estados Unidos, particularmente sobre a utilização de uma programação baseada em algoritmos para a análise de DNA 
Isso seria facilitado se o próprio software utilizado pudesse dar informações sobre as razões que sustentaram a decisão em uma linguagem compreensível para seres humanos. Para isso a chamada Explainable Artificial Intelligence (Inteligência Artificial Explicável) - que (até agora) não está disponível - poderia ser útil. ${ }^{83}$

Um controle judicial eficaz da decisão também é dificultado, em muitos casos, pelo fato de que os algoritmos empregados não são revelados aos tribunais, mas, mesmo que isso ocorresse, possivelmente eles não seriam compreensíveis para os juízes, que comumente não são especialistas em algoritmos. Atualmente não há providências jurídicas sobre se e até que ponto os algoritmos, incluindo o código-fonte - o programa que traduz os algoritmos em software operacional devem ser revelados ao tribunal. ${ }^{84} 85$ Até agora tampouco está esclarecido se, ao menos, os critérios e máximas em que se baseiam os algoritmos - bem como, no caso de algoritmos aprendentes, os programas de treinamento - precisam ser disponibilizados ao tribunal. Também será preciso esclarecer até que ponto se podem obter informações suficientes unicamente com base nos algoritmos. Se, p. ex., só se divulga o código-fonte, não se pode depreender dele como transcorreu a formação da decisão digital.

Via de regra, os destinatários de um ato administrativo não conhecem os algoritmos porque falta uma obrigação de divulgá-los a eles. Os algoritmos são desconhecidos especialmente em casos de reconhecimento da proteção dos algoritmos como segredos oficiais. ${ }^{86}$ Consequentemente, só em casos excepcionais os afetados conseguem alicerçar um recurso judicial com erros de software e na entrada do input.

As dificuldades são particularmente grandes na utilização de sistemas aprendentes. No caso deles, muitas vezes nem especialistas nem mesmo os programadores sabem ou compreendem em detalhes como o software empregado

no processo penal. Quanto a decisões judiciais e literatura relevantes, veja KWONG. The Algorithm Says You Did It: The Use of Black Box Algorithms to Analyze Complex DNA Evidence. Harvard Journal of Law \& Technology, v. 31, 2017. p. 274 ss.

83 Quanto aos esforços feitos para tanto, veja WISCHMEYER. Regulierung intelligenter Systeme. AöR, v. 143, n. 1, 2018. p. 46 ss., com referências adicionais na nota 247.

84 Cf. HOEREN; NIEHOFF. KI und Datenschutz - Begründungserfordernisse automatisierter Entscheidungen. Rechtswisssenschaft, 2018. p. 55 ss.

85 Isso exigiria, eventualmente, a abertura legal de um processo em segredo de justiça (uma construção desse tipo se encontra no $\$ 99$ do Código de Jurisdição Administrativa) em casos nos quais se devem proteger interesses legítimos de manutenção do sigilo.

86 Para os sistemas de gestão de risco no direito tributário, o §88, 5, 3 do Código Geral de Impostos até prevê explicitamente que seus detalhes não devem ser relatados na medida em que isso ameaçar a igualdade e legalidade da tributação. Quanto a isso, veja, pars pro toto, MARTINI; NINK. Wenn Maschinen entscheiden - vollautomatisierte Verfahren und der Persönlichkeitsschutz. NVwZ-extra, v. 10, n. 1, 2017. p. 10. 
no presente - eventualmente modificado pelo aprendizado desde a programação inicial - operou e que efeitos isso causou. Andrew Tutt afirma o seguinte, fazendo referência específica aos sistemas aprendentes:

Mesmo que possamos descrever plenamente o que os faz funcionar, os mecanismos reais pelos quais eles implementam suas soluções provavelmente permanecerão opacos: dificeis de prever e, às vezes, dificeis de entender. E à medida que se tornam mais complexos $\mathrm{e}$ mais autônomos, essa dificuldade irá aumentar. ${ }^{87}$

Por conseguinte, frente a decisões automatizadas, só é de maneira limitada possível alcançar uma proteção jurídica efetiva iniciando um controle judiciário num caso individual. Tanto mais importante se torna que garantes da exatidão de decisões automatizadas sejam introduzidos em nível sistêmico, e também preventivamente (Legitimation by Design). ${ }^{88}$ Esses garantes deveriam atuar como compensadores da ausência de garantes da exatidão que estão disponíveis em decisões não automatizadas para assegurar a responsabilidade, possibilidade de controle e correção de erros.

Até agora isso não está assegurado e provavelmente também só é possível em grau limitado. Para ter garantias contra erros entram em cogitação, p. ex., providências para que os sistemas possam controlar seus próprios processos, eventualmente em colaboração com seres humanos. ${ }^{89}$ Também faz sentido introduzir uma avaliação institucionalmente estabelecida das consequências dos algoritmos dos programas usados para decisões administrativas automatizadas. Uma avaliação das consequências dos procedimentos operacionais previstos está contida no art. 35ํㅡ. par. 3a do RGPD-UE e no $\$ 67$ da Lei Federal de Proteção de Dados (nova) para o processamento automatizado sistemático e abrangente de aspectos pessoais, p. ex., no caso de definição de perfis (profiling), mas ela está limitada ao processamento de dados pessoais. Esse instituto não se aplica de modo geral, nem mesmo especial, a decisões administrativas. Para tanto seria preciso criar um instituto - ancorado no direito processual - da avaliação

87 TUTT, Andrew. An FDA for Algorithms. Administrative Law Review, v. 69, 2017. p. 83; 102.

88 Cf., pars pro toto, YEUNG. Towards an Understanding of Regulation by Design. In: BROWNSWORD; YEUNG (Ed.). Regulating Technologies. New York: Hart Publishing, 2008. p. 79 ss.; HILDEBRANDT. Law as Computation in the Era of Artificial Legal Intelligence: Speaking Law to the Power of Statistics. University of Toronto Law Journal, v. 68, 2018. p. 16, exige, p. ex., a instituição de "Legal Protection by Design", que "visa salvaguardar nossa capacidade - como indivíduos - de questionar sistemas de decisão automatizada proporcionando tempo e espaço para testar e contestar o funcionamento desses sistemas".

89 Quanto a isso, veja WISCHMEYER. Regulierung intelligenter Systeme. AöR, v. 143, n. 1, 2018. p. 61. 
prospectiva das consequências. No caso de sistemas aprendentes, porém, sua implementação acarreta problemas especiais, ${ }^{90}$ caso não haja também possibilidades de avaliações contínuas das consequências no decorrer do tempo.

Outras possibilidades consistiram em obrigações de certificação e auditoria dos sistemas de TI utilizados pela administração pública para decisões automatizadas por parte de um órgão especializado independente. ${ }^{91}$ No caso de sistemas aprendentes, entretanto, um controle ex ante não seria suficiente, pois o funcionamento do sistema algorítmico por programas de aprendizado pode, como se mencionou, ser modificado continuamente. ${ }^{92}$ Neste caso, seriam importantes, ao menos, obrigações de protocolização e preservação de provas da execução concreta do programa. ${ }^{93}$ Também se deve pensar em conceder a especialistas independentes possibilidades sistemáticas de testar os algoritmos concretamente empregados, ${ }^{94}$ p. ex., para verificar se contêm discriminações ocultas, baseiam-se em critérios estranhos ao assunto ou omitem parâmetros decisórios importantes.

A falta de tais providências ou dispositivos com direcionamento sistêmico ${ }^{95}$ mostra que o ordenamento jurídico alemão - e o mesmo se aplica a outros ordenamentos jurídicos - ainda não está preparado para as particularidades dos bens protegidos por lei no contexto do emprego de decisões administrativas ou judiciais automatizadas. Para reunir experiências, faria sentido utilizar o instrumento da definição experimental de normas. ${ }^{96}$

90 Quanto a isso, veja CONRAD. Künstliche Intelligenz - Die Risiken für den Datenschutz. DuD, 2017. p. 744.

91 Propostas nesse sentido se encontram, p. ex., em SCHERER. Regulating Artificial Intelligence Systems: Risks, Challenges, Competencies, and Strategies. Harvard Journal of Law \& Technology, v. 29, 2016. p. 393 ss.; MARTINI; NINK. Wenn Maschinen entscheiden - vollautomatisierte Verfahren und der Persönlichkeitsschutz. NVwZ-extra, v. 10, n. 1, 2017. p. 14. Para o âmbito americano, Tutt sugeriu criar uma instituição poderosa, tomando como modelo a Federal Drug Administration, para fazer uma verificação prévia de algoritmos "perigosos”, e isso para o emprego geral desses algoritmos, e não especialmente sua utilização em âmbitos do Estado.

92 Quanto à possibilidades do controle ex post, veja MARTINI; NINK. Wenn Maschinen entscheiden vollautomatisierte Verfahren und der Persönlichkeitsschutz. NVwZ-extra, v. 10, n. 1, 2017. p. 12.

93 Segundo MARTINI; NINK. Wenn Maschinen entscheiden - vollautomatisierte Verfahren und der Persönlichkeitsschutz. NVwZ-extra, v. 10, n. 1, 2017. p. 13.

94 Quanto às possibilidades, veja MARTINI; NINK. Wenn Maschinen entscheiden - vollautomatisierte Verfahren und der Persönlichkeitsschutz. NVwZ-extra, v. 10, n. 1, 2017. p. 12; HILDEBRANDT. Law as Computation in the Era of Artificial Legal Intelligence: Speaking Law to the Power of Statistics. University of Toronto Law Journal, v. 68, 2018. p. 16.

95 Estímulos para isso se encontram em WISCHMEYER. Regulierung intelligenter Systeme. AöR, v. 143, n. 1, 2018. p. 46 ss., e (nota 75) Parte 3.

96 Quanto a isso, veja HOFFMANN-RIEM. Innovation und Recht: Recht und Innovation. Heidelberg: Mohr Siebeck, 2016. p. 362 ss., com mais referências. 


\section{Requisitos para uma execução de decisões automatizadas}

Algoritmos também podem ser utilizados para garantir automaticamente o cumprimento dos requisitos legais de decisões já tomadas por parte de seus destinatários ou a sanção automática do incumprimento. Um entre vários recursos para a implementação automatizada de regras é a tecnologia Blockchain. ${ }^{97}$ Existem diferenças substanciais para com as vias usuais de assegurar o cumprimento do direito.

Na medida em que o ordenamento jurídico e/ou as decisões nele apoiadas visam ao cumprimento de prescrições por parte de quem é afetado por uma norma, via de regra se tem pressuposto, até agora, que as pessoas afetadas tenham conhecimento (possam tê-lo) das vinculações jurídicas de seu comportamento e, neste sentido, tomem (possam tomar) decisões autodeterminadas sobre o cumprimento da regra. Caso uma regra criada contratual ou legalmente seja infringida, isso pode ser sancionado socialmente e/ou também juridicamente, $p$. ex., mediante uma obrigação de pagar indenização, uma medida de execução judicial ou a fixação de uma multa pecuniária ou sanção penal.

Contudo, via de regra a iminência de uma medida de execução só é conhecida pelas pessoas afetadas se tiver havido uma ameaça anterior de sua execução - como ocorre, via de regra, em decisões administrativas incriminatórias. O conhecimento de uma sanção iminente é um dos meios para preservar a autonomia das pessoas afetadas: como seres pensantes e também capazes de agir eticamente, elas mesmas podem decidir se irão seguir as prescrições jurídicas ou se existem razões para não fazer isso e, eventualmente, correr o risco de sofrer uma sanção. A possibilidade de recusar o cumprimento da regra pode, em casos excepcionais, ser até desejável, p. ex., quando um comportamento que esteja em conformidade com a regra se aproxime mais do sentido da regra do que seu cumprimento "cego". Isso pode ocorrer nas situações dilemáticas já mencionadas. Tem-se um exemplo relativamente inócuo disso quando, no trânsito, se descumpre uma regra do Código de Trânsito para evitar um acidente que, do contrário, seria iminente. Para situações especiais assim, Niklas Luhmann cunhou o termo "ilegalidade útil". ${ }^{98}$

A possibilidade de uma decisão autônoma fica excluída na medida em que um sistema decisório baseado em algoritmos esteja concebido de tal

97 Quanto a ela, veja, de modo geral, a referência na nota 8, bem como, no presente contexto, YEUNG. Dürrezeit für Freiheit im Rahmen von Recht und Gesetz? Blockchain, Transaktionssicherheit und das Versprechen automatisierter Rechtsdurchsetzung. In: OTTO; GRÄF (Ed.). 3TH1CS: Die Ethik der digitalen Zeit. Berlim: iRights Media, 2018. p. 154 ss.

98 LUHMANN. Funktion und Folgen formaler Organisation. 2. ed. Berlim: Duncker \& Humblot GmbH, 1972. p. 304 ss. 
forma que a sanção de uma infração de regra ocorra automaticamente e sem conhecimento prévio das pessoas afetadas. Isto porque existem possibilidades de restringir a capacidade de uma pessoa já pela própria tecnologia. ${ }^{99}$ Neste caso, não se pressupõe mais um ato voluntário para decidir sobre o cumprimento ou incumprimento de prescrições normativas ou um processo interativo para verificar os requisitos relativos ao cumprimento. Exemplos disso são o emprego da tecnologia de filtragem para evitar violações da lei, ${ }^{100}$ associado ao bloqueio do comportamento - como ex., a divulgação de conteúdos odientos ou racistas na internet (Content Curation [Curadoria de Conteúdo]) ou o impedimento da utilização não permitida de obras protegidas pelo direito autoral. ${ }^{101}$ Outros exemplos de tecnorregulação por design ocorrem nos chamados Smart Contracts (Contratos Inteligentes). ${ }^{102}$ Neles pode estar previsto, p. ex., que um imóvel alugado seja automaticamente trancado no caso de atraso do pagamento do aluguel, de modo que ele não possa mais ser usado pelo locatário. Um contrato de leasing de um automóvel pode dar o direito de inserir uma tecnologia (sensor ou conectividade apropriada) que faça com que o automóvel objeto do leasing não possa ser ligado caso uma prestação que está vencendo não seja paga.

Se a capacidade de uma pessoa já seja restringida dessa maneira pela própria tecnologia, para o sucesso do controle não há necessidade nem mesmo da tomada de conhecimento das regras inseridas nos algoritmos por parte das pessoas afetadas. Em tais casos, o controle do comportamento não se dá com a ajuda das prescrições típicas para o efeito de normas jurídicas nas categorias de ter permissão/não ter permissão ou dever, e sim diretamente pela limitação da capacidade (factual). Aposta-se no efeito coercivo de sistemas tecnológicos. ${ }^{103}$ Essa espécie de regras tecnológicas é self-executing (autoexecutante). ${ }^{104} \mathrm{Seu}$ emprego é - diferentemente do que ocorre na sanção de infrações da lei segundo as regras do Código de Processo Civil ou Administrativo - expressão de uma

99 Quanto a isso, de modo geral, YEUNG. Towards an Understanding of Regulation by Design. In: BROWNSWORD; YEUNG (Ed.). Regulating Technologies. New York: Hart Publishing, 2008. p. 81 passim; PASQUALE. Restoring Transparency to Automated Authority. Journal on Telecommunication \& High Technology Law, v. 9, 2011. p. 235; 248 ss.

100 Detalhes sobre isso em KASTL. Filter: Fluch oder Segen? Möglichkeiten und Grenzen von Filtertechnologien zur Verhinderung von Rechtsverletzungen. GRUR, 2016. p. 671 ss.

101 Quanto a isso, veja DANKERT. Normative Technologie in sozialen Netzwerkdiensten. KritV, 2015. p. 49; 56 ss.; TENE; POLONETSKY. Taming the Golem: Challenges of Ethical Algorithmic Decision-Making. North Carolina Journal of Law \& Technology, v. 19, 2017. p. 125; 154 passim.

102 Quanto a eles, veja as referências na nota 9.

103 YEUNG. Dürrezeit für Freiheit im Rahmen von Recht und Gesetz? Blockchain, Transaktionssicherheit und das Versprechen automatisierter Rechtsdurchsetzung. In: OTTO; GRÄF (Ed.). 3TH1CS: Die Ethik der digitalen Zeit. Berlim: iRights Media, 2018. p. 165.

104 Quanto a isso, cf. SCHULZ; DANKERT. Die Macht der Informationsintermediäre. Bonn: Friedrich-EbertStiftung, 2016. II.3.B. 
assimetria de poder: os sancionados não têm oportunidade de levantar objeções - nem contra a regra supostamente violada nem contra sua aplicação no caso concreto. ${ }^{105}$

Esses contratos limitam a autonomia comportamental e também levantam, por consequência, questões a respeito da legitimação de tais procedimentos jurídicos. Mencione-se isso aqui apenas a título de lembrete.

\section{Governança por algoritmos}

Por fim, situamos a utilização de algoritmos (também) em decisões jurídicas - que na Alemanha só ocorreu de modo incipiente, mas, com grande probabilidade, será mais acentuadamente ampliada no futuro - no contexto da discussão geral sobre a governança. ${ }^{106} 0$ termo "governança" - que está sendo cada vez mais ampliado em seus contornos - se refere a modalidades de solução de problemas relacionadas não só à ação do governo, mas também à de outros, p. ex., à ação de sujeitos privados. Ele diz respeito a formas e mecanismos de coordenação e controle social, econômico, político e também tecnológico. Implica processos de enfrentamento de problemas com foco especial nas interdependências existentes e na interação de diversos atores, bem como dos padrões de coordenação das ações nela utilizados.

Comumente se elaboram quatro modelos de governança: hierarquia, mercado/concorrência, negociação e rede. Ultimamente uma série de autores também relacionam o conceito de governança com os padrões de solução de problemas observáveis no desenvolvimento e na aplicação de algoritmos. No âmbito linguístico anglo-saxão se fala, por um lado, de Governance of Algorithms, referindo-se particularmente às modalidades do surgimento de algoritmos. ${ }^{107}$ Neste sentido, recomenda-se falar de "governança de algoritmos" em português. Além disso, fala-se também de Governance by Algorithms. ${ }^{108}$ Neste sentido, o que

105 HILDEBRANDT. Law as Computation in the Era of Artificial Legal Intelligence: Speaking Law to the Power of Statistics. University of Toronto Law Journal, v. 68, 2018. p. 25 ss.; 29.

106 Quanto a ela, veja SCHUPPERT, Gunnar Folke. Governance und Rechtsetzung. Baden-Baden: Nomos Verlagsgesellschaft, 2011; SCHUPPERT, Gunnar Folke. Alles Governance oder was? Baden-Baden: Nomos Verlagsgesellschaft, 2011; BENZ, A.; DOSE, N. (Ed.). Governance: Regieren in komplexen Regelsystemen. 2. ed. Wiesbaden: VS Verlag, 2010; HOFFMANN-RIEM. Die Governance-Perspektive in der rechtswissenschaftlichen Innovationsforschung. Baden-Baden: Nomos Verlagsgesellschaft, 2011.

107 Quanto a isso, veja SAURWEIN; JUST; LATZER. Governance of Algorithms: Options and Limitations. DOI, 2015. p. 35 s.

108 Quanto a isso, veja JUST; LATZER. Governance by Algorithms: Reality Construction by Algorithmic Selection on the Internet. Media, Culture \& Society, v. 29, 2016. p. 1 ss.; BRAUN BINDER. Algorithmic Regulation - Der Einsatz algorithmischer Verfahren im staatlichen Steuerungskontext. In: HILL; WIELAND 
está em jogo são o controle ou a regulação de comportamentos e estruturas com ajuda de algoritmos ou por algoritmos.

A governança de algoritmos foi abordada acima especialmente na descrição dos processos de desenvolvimento de algoritmos incluindo a entrada de inputs (veja, anteriormente, seção 5). Por outro lado, nas seções 7 e 8 se tratou de exemplos de governança por algoritmos, neste caso limitados a modalidades de decisões de caráter jurídico. Neste sentido, caso se empreguem algoritmos, isso também pode ocorrer no contexto da utilização complementar de outras modalidades de governança, como a hierarquia (p. ex., decisões baseadas em algoritmos sobre a arrecadação de impostos ou a implementação de obrigações jurídicas). Da mesma forma, a influência do direito baseada em algoritmos pode se relacionar com processos e estruturas do mercado e da concorrência, mas também com a utilização de sistemas de negociação ou no marco de redes. Uma combinação de diversas modalidades de governança não é uma particularidade do emprego de algoritmos, e sim um fenômeno amplamente disseminado.

Para a prática e a ciência do direito, vale a pena dar uma atenção especial à governança por algoritmos, pois o emprego de algoritmos se distingue de forma juridicamente relevante de outras modalidades e meios de influenciar comportamentos e estruturas e levanta problemas especiais. Neste sentido, remete-se particularmente às dificuldades já mencionadas da acessibilidade e compreensibilidade de algoritmos, à imputabilidade e responsabilidade bem como à transparência e ao controle de decisões baseadas em algoritmos, mas também aos problemas correlatos das assimetrias na distribuição do poder.

A utilização crescente e aplicada a outras áreas de decisões baseadas em algoritmos exige providências no ordenamento jurídico para preservar princípios fundamentais para um Estado Democrático de Direito. Neste marco também se colocam perguntas a respeito da asseguração de legitimação democrática. John Danaher chegou até a falar de uma Threat of Algocracy (Ameaça da Algocracia). ${ }^{109}$ Com essa expressão ele se refere a uma situação em que sistemas fundados em algoritmos estruturem e limitem digitalmente as possibilidades de participação humana e a compreensibilidade de decisões e, em consequência, as possibilidades

(Ed.). Zukunft der Parlamente. Berlim: Duncker \& Humblot GmbH, 2018. p. 107 ss.; YEUNG, Karen. Algorithmic Regulation: A Critical Interrogation, Regulation \& Governance. 2017. Disponível em: http:// onlinelibrary.wiley.com/journal/10.1111/(ISSN)1748-5991; LENK. Formen und Folgen algorithmischer Public Governance. In: KAR; THAPA; PARYCEK (Ed.). (Un)Berechenbar? Algorithmen und Automatisierung in Staat und Gesellschaft. Berlim: Kompetenzzentrum Öffentliche IT, 2018. p. 228 ss.

109 DANAHER. The Threat of Algocracy: Reality, Resistance and Accommodation. Philosophy \& Technology, v. 29, 2016. p. 245 ss. A escolha dos termos se apoia em ANEESH, A. Global labor: algocratic modes of organization. Sociological Theory, v. 27, 2009. p. 347 ss. 
de ação das pessoas afetadas. ${ }^{110}$ No texto citado ele se mostra muito pessimista em relação às possibilidades de dar conta desse problema.

Antes de se seguir essa avaliação, dever-se-iam buscar soluções para conceber e utilizar estruturas de regulação para o emprego de decisões baseadas em algoritmos que possibilitem preservar as vantagens dessas decisões sem abrir mão de requisitos do Estado de Direito e da democracia. Isso constitui um grande desafio.

\title{
The legitimacy of legal decisions in the use of Legal Technology
}

\begin{abstract}
Legal Technology (Legal Tech) refers to the use of digital techniques for applying and enforcing the law. For lawyers, a market is currently emerging for new legal services. In addition, public administrations and the courts are also using the possibilities afforded by digitalization. The article discusses the enhancement of algorithms into learning algorithms, as well as the use of big data. It analyzes the differences between human decisions as social constructs and algorithmic decisions as technical constructs. It also describes the opportunities and difficulties associated with the modelling of law in digital software. Current rules contained in the EU General Data Protection Regulation and in the German law of public administration, but also the automated sanctioning of violations of the law in the area of smart contracts, serve as examples for approaches that are now being practiced.
\end{abstract}

Keywords: Legal Technology. Law Enforcement. Algorithms. Big data. Decision making.

Contents: 1 Legal Technology as a phenomenon of digitalization of the way of dealing with law $\mathbf{2}$ Intelligent systems based on algorithms - $\mathbf{3}$ A special case: the use of big data - $\mathbf{4}$ Functions of law - 5 Guarantee of binding to the rules in the form of social and technological constructs $-\mathbf{6}$ Legitimation requirements - $\mathbf{7}$ Requirements for automated decisions - $\mathbf{8}$ Requirements for automated decision making - 9 Governance by algorithms - References

\section{Referências}

AHRENDT, Christian. Alte Zöpfe neu geflochten. Das materielle Recht in der Hand von Programmierern. NJW, 2017.

ALPAYDIN, Ethem. Machine learning. Cambridge: MIT Press, 2016.

ANEESH, A. Global labor: algocratic modes of organization. Sociological Theory, v. 27, 2009.

BENZ, A.; DOSE, N. (Ed.). Governance: Regieren in komplexen Regelsystemen. 2. ed. Wiesbaden: VS Verlag, 2010.

BERGER, Ariane. Der automatisierte Verwaltungsakt. NVwZ, 2018.

110 DANAHER. The Threat of Algocracy: Reality, Resistance and Accommodation. Philosophy \& Technology, v. 29, 2016. p. 246; 249; 251. 
BITKOM. Künstliche Intelligenz verstehen als Automation des Entscheidens. Berlin: Bitkom, 2017. Disponivel em: https://www.bitkom.org/Bitkom/Publikationen/Kuenstliche-Intelligenz-verstehen-alsAutomation-des-Entscheidens.html. Acesso em: 31 maio 2018.

BOEHME-NEßLER, Volker. Die Macht der Algorithmen und die Ohnmacht des Rechts: Wie die Digitalisierung das Recht relativiert. NJW, 2017.

BOSTROM, Nick. Superintelligence: Paths, Dangers, Strategies. Oxford: OUP Oxford, 2013.

BOZDAG, Engin. Bias in Algorithm Filtering and Personalization. Ethics and Information Technology, v. 15, 2013.

BRAUN BINDER. Vollständig automatisierter Erlass eines Verwaltungsaktes und Bekanntgabe über Behördenportale. DÖV, v. 21, 2016.

BREIDENBACH; GLATZ (Ed.). Rechtshandbuch Legal Tech. Munich: C.H.Beck, 2018.

BROWNSWORD; YEUNG (Ed.). Regulating Technologies. New York: Hart Publishing, 2008.

BUCHHOLTZ, Gabriele. Legal Tech: Chancen und Risiken der digitalen Rechtsanwendung. JuS, 2017.

BULL, Hans Peter. Der „vollständig automatisiert erlassene” Verwaltungsakt - zur Begriffsbildung und rechtlichen Einhegung von E-Government. DVBL, p. 409-417, 2017.

BUMKE; RÖTHEL (Ed.). Autonomie im Recht: Gegenwartsdebatten über einen rechtlichen Grundbegriff. Heidelberg: Mohr Siebeck, 2017.

BUNDESMINISTERIUM FÜR VERKEHR UND DIGITALE INFRASTRUKTUR. Ethik-Kommission automatisiertes und vernetztes Fahren. Berlim: BMVI, 2017.

BUNDESREGIERUNG. Digitale Verwaltung. Berlim: BT-Drucks, 2014.

CHRISTENSEN; KUDLICH. Theorie richterlichen Begründens. Berlim: Duncker \& Humblot GmbH, 2001.

COLE, Tim. Digitale Transformation. Munich: Vahlen, 2015.

CONRAD. Künstliche Intelligenz - Die Risiken für den Datenschutz. DuD, 2017.

DANAHER. The Threat of Algocracy: Reality, Resistance and Accommodation. Philosophy \& Technology, v. 29, 2016.

DANKERT. Normative Technologie in sozialen Netzwerkdiensten. KritV, 2015.

EGBERT. Siegeszug der Algorithmen? APuZ, n. 32/33, 2017.

ERNST. Algorithmische Entscheidungsfindung und personenbezogene Daten. JZ, 2017.

ERTEL, Wolfgang. Grundkurs Künstliche Intelligenz. 4. ed. New York: Springer, 2016.

ESCHENBRUCH. Smart Contracts. NZBau, 2018.

FRESE. Recht im zweiten Maschinenzeitalter. NJW, 2015.

FRIES, Martin (Ed.). Smart Contracts. Heidelberg: Mohr Siebeck, 2018.

FRIES, Martin. PayPal Law und Legal Tech - was macht die Digitalisierung mit dem Privatrecht? NJW, 2016. GOODFELLOW; BENGIO; COURVILLE. Deep Learning. Cambridge: MIT Press, 2016. 
HARTUNG; BUES; HALBLEIB (Ed.). Legal Tech: Die Digitalisierung des Rechtsmarkts. Munich: C.H.Beck, 2018.

HAWKING, Stephen. Kurze Antworten auf große Fragen. 4. ed. Stuttgart: Klett-Cotta, 2018.

HECKELMANN. Zulässigkeit und Handhabung von Smart Contracts. NJW, 2018.

HELBICH. Rechtsfragen der „automatisierten” Ermessensausübung im Steuerrecht. DStR, 2017.

HERMSTRÜWER, Yoan. Informationelle Selbstgefährdung. Heidelberg: Mohr Siebeck, 2016.

HERZOG; SCHLOTHAUER; WOHLERS (Ed.). Rechtsstaatlicher Strafprozess und Bürgerrechte. Berlim: Duncker \& Humblot GmbH, 2016.

HILDEBRANDT. Law as Computation in the Era of Artificial Legal Intelligence: Speaking Law to the Power of Statistics. University of Toronto Law Journal, v. 68, 2018.

HILL; WIELAND (Ed.). Zukunft der Parlamente. Berlim: Duncker \& Humblot GmbH, 2018.

HOEREN; NIEHOFF. KI und Datenschutz - Begründungserfordernisse automatisierter Entscheidungen. Rechtswisssenschaft, 2018.

HOFFMANN-RIEM (Ed.). Big data: Regulative Herausforderungen. Baden-Baden: Verlagsgesellschaft, 2018. HOFFMANN-RIEM. Die Governance-Perspektive in der rechtswissenschaftlichen Innovationsforschung. Baden-Baden: Nomos Verlagsgesellschaft, 2011.

HOFFMANN-RIEM. Innovation und Recht. Recht und Innovation. Heidelberg: Mohr Siebeck, 2016.

HOFFMANN-RIEM. Maßstabsergänzung bei der Rechtsanwendung: eine methodische Notwendigkeit. Festschrift für Hans-Joachim Koch, 2014.

HOFFMANN-RIEM. Verhaltenssteuerung durch Algorithmen: eine Herausforderung für das Recht. AöR, v. 142, 2017.

HOFFMANN-RIEM. Wirkungsorientierte Rechtswissenschaft. ZfRSoz, 2018.

HOFFMANN-RIEM; SCHMIDT-AßMANN; VOßKUHLE (Ed.). Grundlagen des Verwaltungsrechts. 2. ed. Munich: C.H.Beck 2012.

JUST; LATZER. Governance by Algorithms: Reality Construction by Algorithmic Selection on the Internet. Media, Culture \& Society, v. 29, 2016.

KAR; THAPA; PARYCEK (Ed.). (Un)Berechenbar? Algorithmen und Automatisierung in Staat und Gesellschaft. Berlim: Kompetenzzentrum Öffentliche IT, 2018.

KASTL. Filter: Fluch oder Segen? Möglichkeiten und Grenzen von Filtertechnologien zur Verhinderung von Rechtsverletzungen. GRUR, 2016.

KEESE, Christoph. Silicon Germany: Wie wir die digitale Transformation schaffen. Munich: Albrecht Knaus Verlag, 2016.

KISCHEL, Uwe. Die Begründung. Heidelberg: Mohr Siebeck, 2003.

KITCHIN. Thinking Critically about and Researching Algorithms. Information, Communication \& Society, 2016.

KLAFKI; WÜRKERT; WINTER (Ed.). Digitalisierung und Recht. Hamburg: Bucerius Law School Press, 2017. KLATT; SCHMIDT. Spielräume im öffentlichen Recht. Heidelberg: Mohr Siebeck, 2010.

KLEY; KIRSTE. Kontexte der Demokratie: Herrschaftsausübung in Arbeitsteilung. VVDStRL, v. 77, 2018. 
KOLANY-RAISER; HEIL; ORVAT; HOEREN (Ed.). Big data und Gesellschaft: Eine multidisziplinäre Annäherung. New York: Springer VS, 2018.

KOPP; RAMSAUER. Verwaltungsverfahrensgesetz. 19. ed. Munich: C.H.Beck, 2018.

KOTSOGLOU. Subsumtionsautomat 2.0. JZ, 2014.

KUNTZ. Recht als Gegenstand der Rechtswissenschaft und performative Rechtserzeugung. AcP, 2016.

KWONG. The Algorithm Says You Did It: The Use of Black Box Algorithms to Analyze Complex DNA Evidence. Harvard Journal of Law \& Technology, v. 31, 2017.

LUHMANN. Funktion und Folgen formaler Organisation. 2. ed. Berlim: Duncker \& Humblot GmbH, 1972.

MARTINI; NINK. Wenn Maschinen entscheiden - vollautomatisierte Verfahren und der Persönlichkeitsschutz. NVwZ-extra, v. 10, n. 1, 2017.

MAYER-SCHÖNBERGER; CUKIER. Big data. A Revolution That Will Transform How We Live, Work and Think. Boston: Houghton Mifflin Harcourt, 2013.

MERTEN; PAPIER (Ed.). Grundrechte in Deutschland: Allgemeine Lehren I. Munich: C.H.Beck, 2006.

MÜLLER. Bitcoin, Blockchain und Smart Contracts. ZfIR, 2017.

MÜLLER; CHRISTENSEN. Juristische Methodik: Grundlagen für die Arbeitsmethoden der Rechtspraxis. 11. ed. Berlim: Duncker \& Humblot GmbH, 2013.

MÜLLER-HENGSTENBERG; KIRN. Intelligente "Software-Agenten": Eine neue Herausforderung für unser Rechtssystem? Multimedia \& Recht, 2014.

MÜLLER-HENGSTENBERG; KIRN. Rechtliche Risiken autonomer und vernetzter Systeme. Berlim: Walter de Gruyter, 2016.

OTTO; GRÄF (Ed.). 3TH1CS: Die Ethik der digitalen Zeit. Berlim: iRights Media, 2018.

PASQUALE. Restoring Transparency to Automated Authority. Journal on Telecommunication \& High Technology Law, v. 9, 2011.

PFLIEGL; SEIBT. Die digitale Transformation findet statt! e\&i Elektrotechnik und Informationstechnik, v. 7, 2017.

PIEPER. Die Vernetzung autonomer Systeme im Kontext von Vertrag und Haftung. InTeR, 2016.

POSCHER. Eingriffsschwellen im Recht der inneren Sicherheit. Die Verwaltung, v. 41, 2008.

PRECHT, Jäger. Hirten, Kritiker. Eine Utopie für die digitale Gesellschaft. Munich: Goldmann Verlag. 2018.

RAABE; WACKER. Recht ex machina: Formalisierung des Rechts im Internet der Dienste. New York: Springer, 2012.

RADEMACHER. Predictive Policing im deutschen Polizeirecht. AöR, v. 142, 2017.

RADEMACHER; WISCHMEYER (Ed.). Regulating Artificial Intelligence. New York: Springer, 2019.

REICHWALD; PFISTERER. Autonomie und Intelligenz im Internet der Dinge. CR, 2016.

ROLF, Arno. Weltmacht Vereinigte Daten: Die Digitalisierung und big data verstehen. Berlim: Metropolis Verlag, 2018.

RUSSELL; NORVIG. Künstliche Intelligenz. 3. ed. Munich: Pearson Studium, 2012.

SAURWEIN; JUST; LATZER. Governance of Algorithms: Options and Limitations. DOI, 2015. 
SCHERER. Regulating Artificial Intelligence Systems: Risks, Challenges, Competencies, and Strategies. Harvard Journal of Law \& Technology, v. 29, 2016.

SCHLIESKY, Utz. Souveränität und Legitimität von Herrschaftsgewalt. Heidelberg: Mohr Siebeck, 2004.

SCHULZ; DANKERT. Die Macht der Informationsintermediäre. Bonn: Friedrich-Ebert-Stiftung, 2016.

SCHUPPERT, Gunnar Folke. Alles Governance oder was? Baden-Baden: Nomos Verlagsgesellschaft, 2011.

SCHUPPERT, Gunnar Folke. Governance und Rechtsetzung. Baden-Baden: Nomos Verlagsgesellschaft, 2011.

STALDER, Felix. Kultur der Digitalität. Berlim: Suhrkamp Verlag AG, 2016.

STELKENS; BONK; SACHS (Ed.). Verwaltungsverfahrensgesetz. 9. ed. Munich: C.H.Beck, 2018.

STENGEL; VAN LOOY; WALLASCHKOWSKI (Ed.). Digitalzeitalter - Digitalgesellschaft: Das Ende des Industriezeitalters und der Beginn einer neuen Epoche. New York: Springer VS, 2017.

SURDIN. Machine Learning and Law. Washington Law Review, v. 89, 2014.

TAEGER (Ed.). Big data \& Co: Neue Herausforderungen für das Informationsrecht. Edewecht: OIWIR Verlag, 2014.

TAEGER (Ed.). Smart World - Smart Law? Weltweite Netze mit regionaler Regulierung. Edewecht: OIWIR Verlag, 2016.

TEGMARK, Max. Life 3.0: Being Human in the Age of Artificial Intelligence. New York: Knopf, 2017.

TENE; POLONETSKY. Big data for All. Northwestern Journal of Technology and Intellectual Property, v. 11, 2013.

TENE; POLONETSKY. Taming the Golem: Challenges of Ethical Algorithmic Decision-Making. North Carolina Journal of Law \& Technology, v. 19, 2017.

TUTT, Andrew. An FDA for Algorithms. Administrative Law Review, v. 69, 2017.

WAGNER. Legal Tech und Legal Robots in Unternehmen und den diese beratenden Kanzleien. BB, 2017. WEBER. Dilemmasituationen beim autonomen Fahren. NZV, 2016.

WESTERMANN, Eike. Legitimation im europäischen Regulierungsverbund. Heidelberg: Mohr Siebeck, 2017.

WISCHMEYER. Informationssicherheitsrecht: IT-Sicherheitsgesetz und NIS-Richtlinie als Bausteine eines Ordnungsrechts für die Informationsgesellschaft. Die Verwaltung, v. 50, 2017.

WISCHMEYER. Regulierung intelligenter Systeme. AöR, v. 143, n. 1, 2018.

YEUNG, Karen. Algorithmic Regulation: A Critical Interrogation, Regulation \& Governance. 2017. Disponível em: http://onlinelibrary.wiley.com/journal/10.1111/(ISSN)1748-5991. 
Informação bibliográfica deste texto, conforme a NBR 6023:2018 da Associação Brasileira de Normas Técnicas (ABNT):

HOFFMAN-RIEM, Wolfgang. A legitimação de decisões jurídicas na utilização de Legal Technology. Direitos Fundamentais \& Justiça, Belo Horizonte, ano 14, n. 42 , p. 75-112, jan./jun. 2020.

Recebido em: 09.05.2020

Aprovado em: 25.05.2020

Cota Convite 